\title{
Techno-economic and carbon emissions analysis of biomass torrefaction downstream in international bioenergy supply chains for co-firing
}

\author{
Athanasios A. Rentizelas ${ }^{a}$, Jun Li ${ }^{b}$ \\ a Department of Design Manufacture and Engineering Management, University of Strathclyde, 75 \\ Montrose street, G1 1XJ, Glasgow, UK. Corresponding author: athanasios.rentizelas@strath.ac.uk \\ ${ }^{\mathrm{b}}$ Department of Chemical and Process Engineering, University of Strathclyde, 75 Montrose street, \\ G1 1XJ, Glasgow, UK. E-mail: jun.li@strath.ac.uk
}

\section{Keywords}

Torrefaction; Biomass; Supply chain; Co-firing; Power generation; Carbon emissions

\begin{abstract}
Ambitious renewable energy targets in European countries drive an increasing biomass demand to a point where domestic resources are insufficient, leading to emergence of international bioenergy supply chains. This work aims to examine the feasibility of biomass torrefaction downstream in longdistance international bioenergy supply chains for co-firing and to investigate the effect of various biomass co-firing ratios on the whole supply and energy conversion system performance from a technical, environmental and economic aspect. A techno-economic analysis together with a $\mathrm{CO}_{2}$ emissions assessment is performed, adopting a whole systems approach. In particular, Palm Kernel Shell biomass from Malaysia is considered for co-firing in UK. Findings indicate that downstream torrefaction is profitable under the current conditions for $100 \%$ biomass and marginally unprofitable for $50 \%$ biomass co-firing. The financial yield exhibits high sensitivity on the price of coal, biomass, Renewable Obligation Certificates, the torrefaction facility investment and biomass sea transportation costs. From an environmental perspective, higher co-firing ratios lead to higher emissions per unit of renewable energy generated. The findings can support policy makers and investors in adopting lower biomass co-firing ratios with torrefaction instead of $100 \%$ biomass conversion, leading to improved environmental benefits from a whole system's perspective.
\end{abstract}

\section{Introduction}

Biomass has been identified as one of the main energy sources to support the ambitious targets of increasing the share of renewable energy generation and reducing the Greenhouse Gas (GHG) emissions in many countries. The EU has set up the target for renewable energy contribution to $20 \%$ of the energy generation mix by the year 2020 and almost 51\% of the increase from the 2014 level is expected to be achieved using biomass [1]. Similarly, the UK target for $15 \%$ renewable energy by 2020 will require half of the increase from the actual 5.2\% in 2013 to be achieved using biomass [2]. Official sources estimate that $70 \%-87 \%$ of the UK biomass requirements in year 2030 will be covered by imported biomass, due to insufficient domestic sources [3]. If one takes into account that most Western European countries face a similar situation with continuously increasing biomass needs and limited domestic supply, it becomes clear that satisfying those needs requires long-distance transportation of biomass from locations beyond Europe. 
Looking at the UK biomass-to-power sector in particular, as of April 2016 there were 2218 MWe of dedicated or co-firing biomass installed, with an additional 2938 MWe awaiting or under construction [4]. One of the most prominent players in this market is Drax power, with $1290 \mathrm{MWe}$ operational and further $645 \mathrm{MWe}$ awaiting construction, all of which concerns conversions of coalto biomass-fuelled units. These figures show the extent of expansion of the biomass-to-power sector in the UK and therefore the scope for investigating the option of importing biomass resources for use in existing coal-powered units.

The need for long distance biomass transportation to Western Europe has been identified and received attention by the academic community during the last decade. Some researchers have focused on the techno-economic aspects of various biomass supply chain configurations from Latin America (eucalyptus) [5], Scandinavia or Eastern Europe to Western Europe (energy crops and forestry residues) [6] Australia, Canada and Russia to Western Europe [7], and Mozambique to Netherlands (eucalyptus and switchgrass) [8]. Researchers have also focused on the GHG effects and energy analysis of the respective supply chain from Malaysia (Palm Kernel Shells - PKS) and Canada (wood pellets) to Netherlands [9]. Currently biomass is commercially transported primarily from US and Canada to Western Europe, as well as from Eastern to Western Europe. The biomass transported is mainly forest residues, in the form of wood pellets or wood chips [5].

One of the potential pathways of generating energy from biomass is co-firing with fossil fuel sources at an existing power plant, usually a coal-fired plant. Co-firing can be considered as a transitional option towards a completely carbon-free power sector, offering advantages with respect to using biomass in dedicated power plants, such as higher thermal efficiency, lower capital costs, and less supply risk because the plant can revert to coal if biomass is insufficient [10]. This opens up an effective pathway to increase the biomass power capacity in the short-term and simplify the technical challenges [11].

However, biomass materials are significantly different from coal with respect to handing and combustion performance: biomass has lower energy density, higher moisture and volatile contents, higher chlorine and potassium contents than coal. Using untreated biomass for co-firing is thus technically complicated, as dedicated cutting mills, biomass burners, and in some cases changes in the boiler are required. The variable fuel quality displayed by biomass affects significantly the boiler performance; therefore, the co-firing ratios are currently kept at lower than $10 \%$ biomass input levels in most cases (energy basis) [10].

In this respect, torrefaction has been identified lately as a promising biomass pre-treatment option to allow increasing the co-firing ratio. By performing torrefaction, the tenacious nature of raw biomass is lost due to the breakdown of the hemicellulose matrix and the length of fibers is decreased during the depolymerization process [12]. Compared to raw biomass or white pellets, torrefied biomass has improved flowability and fluidization behavior; these characteristics facilitate the direct injection of biomass powder into boiler furnaces [13], providing an option for achieving higher biomass co-firing ratios with minor changes to the boiler system. Therefore, torrefaction based biomass co-firing in existing coal-fired power stations has been proposed [14] and the boiler performance after $100 \%$ fuel switch has been investigated [15]. From a logistical perspective, torrefied biomass allows long-term storage without degradation and offers the possibility of utilization of diverse feedstock sources due to the improved end fuel uniformity. The current 
worldwide status of torrefaction facilities has been mapped in [16]. Torrefaction is commonly combined with pelletisation, which requires further energy input requirements in terms of heat and electricity. Typically, torrefaction requires $171 \mathrm{kWh}$ electricity per ton with an extra $22 \mathrm{kWh}$ per ton required for pelletisation [17]; however, the same authors acknowledge that the latter figure can be significantly higher.

A handful of researchers have investigated the integration of torrefaction process in the biomass supply chain. For example, torrefied pellets can be delivered to Netherlands from Latin America at a lower cost compared to wood pellets and pyrolysis oil and can lead to lower energy cost when combined with various energy exploitation pathways [5]. Similarly, integration of torrefaction in a wood-pellet supply chain between Canada and Northwest Europe was found to lead to a $9 \%$ reduction of the feedstock delivered cost [18]. On the other hand, torrefied pellets from Mozambique to Netherlands were found to incur a higher cost than white pellets, with the cost converging in the long term [8]. The cost of supplying torrefied biomass for a pellet-fired CHP plant via train within Sweden was also examined [19]. Ultimately, there is no consensus in the literature on whether torrefaction and pelletisation of biomass in international supply chains reduces the feedstock delivered cost compared to white pellets; rather, it appears to be case specific.

All research up to now has focused on torrefaction of biomass upstream in the feedstock supply chain, close to the area of biomass collection, in order to exploit the logistical advantages of higher density during the long-distance transportation stage of the respective supply chain, usually performed by ship or train [5,8,17-21]. Torrefaction of biomass downstream in the supply chain, i.e. integrated at the biomass end-use location, has not been reported in the literature with the notable exception of [22], where biomass torrefaction at the power plant location for $10 \%$ and $20 \%$ co-firing with coal was considered, but only for domestic medium-distance supply chains in the US.

Downstream torrefaction seems a rather counter-intuitive choice in principle, as the logistical advantages of increased bulk density are lost. On the other hand, there are several advantages related to the combination of downstream torrefaction with co-firing: 1) in an upstream torrefaction supply chain, biomass needs to be pelletised before being transported and then grinded at the enduse location; in downstream torrefaction both these processing stages can be avoided. This means lower investment cost in terms of equipment required, lower energy input due to avoidance of the energy-intensive pelletisation and pellet grinding stages, as well as simplification of the supply chain by removing the related processing stages. The pelletisation stage has very significant energy input requirements (1-1.2 GJ/t dry delivered), which was found to be higher in most cases than the energy required for the sea transportation stage of biomass from Latin America to Netherlands [5]; 2 ) in co-firing plants, use of recycled waste heat for the downstream torrefaction process can improve the overall energy efficiency, thus saving energy that in the case of upstream torrefaction would require electricity from the local grid or burning part of the biomass feedstock itself, therefore leading to self-consumption and reduced biomass availability for the end-use.

Accordingly, it can be concluded that there is a research gap in the current literature regarding (1) the feasibility of torrefaction of biomass downstream in the supply chain, at the energy conversion stage, (2) the environmental implications of such a supply chain design, (3) the effect that different co-firing rates may have on the whole supply and energy conversion system efficiency and (4) the identification of the policy conditions that would render this option feasible from a financial perspective. Therefore, the objective of this work is to examine the advantages, disadvantages and 
feasibility of biomass torrefaction downstream in long-distance international bioenergy supply chains from a techno-economic and carbon emissions perspective, incorporating also the biomass end-use stage. It also aims to investigate the effect that the biomass co-firing ratio may have on the whole supply and energy conversion system performance from a technical, environmental and economic aspect, adopting a whole systems approach. In particular, the case of PKS biomass originating from Malaysia is considered for co-firing in the UK, due to the commercial feedstock availability, high energy density, low moisture and easy-handling properties in its raw form, that allow long-distance transportation without requiring further pre-processing, drying or pelleting. PKS is a process residue produced in the palm oil industry from processing Fresh Fruit Bunches, and is currently an internationally traded commodity.

This work is organised as follows: Section 2 describes the system modelled and the methodology adopted in terms of modelling the biomass supply system, the torrefaction and energy conversion system processes, the system carbon emissions and the investment analysis. Section 3 presents and discusses the results regarding the investment analysis and the system carbon emissions. The results are followed by a sensitivity analysis on the most influential system parameters in section 4 . The work concludes with the conclusions and implications of the findings in section 5 .

\section{System description and methodology}

\subsection{Supply system}

The supply chain schematic can be found in Fig. 1. Grey rectangles indicate physical location change; white rectangles indicate processing or major logistical operations. Transportation operations are indicated on the respective arrows. The scope of the model relative to the supply chain is indicated by the dashed line. The upstream stages of production and transportation of PKS from the Palm plantation up to the export port in Malaysia have not been explicitly modelled; however, the PKS price used in the calculations is on a Free On Board (FOB) basis and therefore includes all these steps from a costing perspective. Furthermore, information on GHG emissions of these supply chain stages has been adapted from the literature [9].

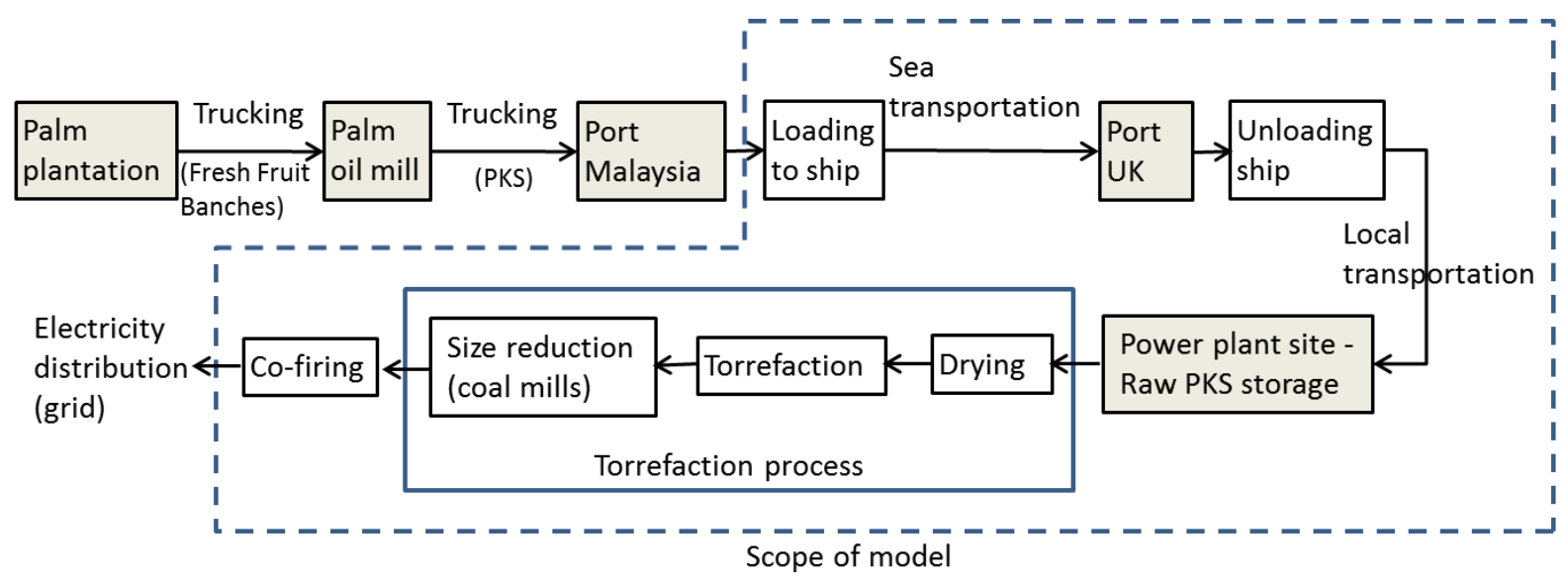

Figure 1. PKS supply chain schematic

The supply chain model starts with PKS being loaded to the ship at the biomass export port, in Malaysia. A Handymax bulk carrier with capacity of $45000 \mathrm{t}$ and $56250 \mathrm{~m}^{3}$ has been assumed to be used, as this ship type usually has self-loading and unloading capability on-board and therefore can 
load also from smaller ports that do not have the appropriate loading infrastructure, providing access to more remote locations with biomass resource availability. Due to the relatively low bulk density of PKS biomass $\left(490 \mathrm{~kg} / \mathrm{m}^{3}\right)$ compared to the marginal cargo density of the ship $\left(800 \mathrm{~kg} / \mathrm{m}^{3}\right)$, volume is the restrictive factor in the sea transportation stage, leading to suboptimal utilisation of the ship capacity. The average distance between the ports in Malaysia and the UK is approximately $16000 \mathrm{~km}$ via Suez. The ship is assumed to be travelling 95\% of the time in non-ECA (Emission Control Area) routes, using Heavy Fuel Oil (HFO), and the rest of the time in ECA routes using Marine Gas Oil (MGO), as lower sulphur content fuel should be used in the latter case. For the route considered in this work, only the part of English Channel and North Sea, if unloading in eastern UK ports, would fall under ECA regulations. Since the sea transportation stage has been found to be one of the major cost, energy use and emissions factors in long distance biomass supply chains [8], the sea transportation cost has been calculated analytically in this work as a time charter by adding a daily charter rate, the fuel cost and other major operational costs (port and canal fees). By analytically modelling the sea transportation stage instead of the aggregate cost figures used by other researchers, the less-than-optimal capacity utilisation due to reduced biomass density can be taken into consideration and its effect can be investigated. Biological and physical biomass losses have been assumed to be negligible, due to the low moisture of PKS that reduces the biological activity and the high efficiency of the sea transportation process that limits the physical material loss. These assumptions are aligned with [9], who did not consider material loss for a long-distance PKS supply chain, and [6], who provided a very low figure of $0.3 \%$ dry matter loss for international shipping of pellets. The actual input data used for the logistical model can be found in Table 1.

Table 1. Main biomass logistics input parameters

\begin{tabular}{|c|c|c|c|}
\hline Main Input Parameters - Logistics & Unit & Value & Source \\
\hline \multicolumn{4}{|l|}{ Sea transportation } \\
\hline Shipping distance & $\mathrm{km}$ & 16000 & [23] \\
\hline Ship nominal capacity - weight & $\mathrm{t}$ & 45000 & Industry sources \\
\hline Ship nominal capacity - volume & $\mathrm{m}^{3}$ & 56250 & Industry sources \\
\hline Shipping cost total & $\mathrm{f} / \mathrm{t}^{*} \mathrm{~km}$ & 0.00107 & Calculated \\
\hline Charter rate & $\$ /$ day & 8000 & Assumption \\
\hline Sailing speed & knots & 13 & Industry sources \\
\hline Duration of sail & days & 28 & {$[23]$} \\
\hline Duration of loading \& unloading & days & 12 & Calculated \\
\hline \multicolumn{4}{|c|}{ Handling \& local transportation at import country } \\
\hline Handling cost at import port & $\mathrm{f} / \mathrm{t}$ & 5.36 & {$[24]$} \\
\hline Truck loading cost & $f / t$ & 1.13 & {$[24]$} \\
\hline Truck nominal capacity -weight & $\mathrm{t}$ & 28 & {$[20]$} \\
\hline Truck nominal capacity - volume & $\mathrm{m}^{3}$ & 93.5 & [20] \\
\hline Trucking cost & $\mathrm{f} / \mathrm{t} * \mathrm{~km}$ & 0.0588 & {$[25]$} \\
\hline \multicolumn{4}{|l|}{ Biomass storage } \\
\hline Height of raw biomass storage piles & $\mathrm{m}$ & 6 & {$[26]$} \\
\hline $\begin{array}{l}\text { Storage space investment cost (pole } \\
\text { structure) }\end{array}$ & $f / m^{2}$ & 88.7 & {$[26]$} \\
\hline \multicolumn{4}{|l|}{ Environmental } \\
\hline Coal $\mathrm{CO}_{2}$ emissions coefficient & $\mathrm{kg} \mathrm{CO}_{2} / \mathrm{kg}$ & 2.21 & [27] \\
\hline
\end{tabular}


$\mathrm{HFO} \mathrm{CO}_{2}$ emissions coefficient

$\mathrm{MGO} \mathrm{CO}_{2}$ emissions coefficient

Sea transportation $\mathrm{CO}_{2}$ emissions

HGV transportation $\mathrm{CO}_{2}$ emissions

Handling $\mathrm{CO}_{2}$ emissions

HFO primary energy conversion factor

\begin{tabular}{|c|c|c|}
\hline $\mathrm{kg} \mathrm{CO}_{2} / \mathrm{kg}$ & 3.114 & [28] \\
\hline $\mathrm{kg} \mathrm{CO} / \mathrm{kg}$ & 3.206 & [28] \\
\hline $\mathrm{kg} \mathrm{CO} / \mathrm{t}^{*} \mathrm{~km}$ & 0.0035 & Calculated \\
\hline $\mathrm{kg} \mathrm{CO} / \mathrm{t}^{*} \mathrm{~km}$ & 0.129 & [29] \\
\hline \multirow[t]{3}{*}{$\mathrm{kg} \mathrm{CO}_{2} / \mathrm{t}$} & 1.4 & [24] \\
\hline & 0.93 & [30] \\
\hline & 0.88 & [30] \\
\hline
\end{tabular}

Once arriving at the UK port, the ship is unloaded and the biomass is transferred to the coal power plant by trucks. The process of loading and unloading the ship is assumed to take 12 days in total, considering an average loading/unloading rate of $400 \mathrm{~m}^{3} / \mathrm{h}$. The storage stage at the port is avoided to reduce overall supply chain costs, as the power plant will have storage space available. Local transportation of biomass from the biomass import port in the UK to the power plant is assumed to be performed using the same logistical chain as for the coal, as it is highly probable that the imported coal for the operation of the coal power plant for the baseline scenario will be unloaded at the same port that minimises the local transportation distance. Biomass is displacing coal as a fuel when considering co-firing scenarios; therefore, the cost for this part of the logistics is not included in the investment analysis for amounts of biomass equal to the coal displaced. However, the total amount of fuel transported in co-firing scenarios is increased compared to the baseline scenario of coal only operation, due to the lower energy density of biomass compared to coal. The additional quantities of fuel required compared to the baseline scenario are assumed to be transported using trucks from the port to the plant, as [31] acknowledged that truck transportation is cheaper than rail for distances shorter than $80 \mathrm{~km}$ (50 miles), and the related cost is included in the investment analysis.

In order to calculate the biomass storage space requirements at the power plant, a Production Order Quantity model has been used, due to the non-instantaneous receipt of biomass and its simultaneous consumption at the power plant. The maximum storage space required is significantly reduced at higher co-firing rates, due to the high consumption rate and the frequent re-supply of biomass. The storage space required for each scenario is assumed to be using space previously allocated to coal storage that is now being displaced by biomass. However, it is assumed that biomass will be stored in a covered pole structure to protect it from the weather elements [26]. It is also assumed that a safety inventory of biomass equal to 7 days of continuous full-load operation is kept at the power plant [22], to protect from potential disruption risk or supply chain uncertainties. It is interesting to note that the safety inventory increases significantly with increasing co-firing rates, whereas the cycle inventory reduces significantly, ultimately leading to a roughly equal requirement for biomass storage space irrespective of the biomass co-firing ratio (see Table 2 ). Biomass storage height is assumed to be $6 \mathrm{~m}$ to avoid the risk of self-ignition. Torrefied biomass is assumed to be stored in the same storage space type as raw biomass, though the torrefaction facility will operate in the same mode and load factor as the power plant, as it utilises recycled waste process heat. Therefore, torrefied biomass production should follow closely the biomass demand. Torrefied biomass cannot be stored for long time periods in pulverised form as it is explosive; therefore, it will be milled when demanded. 
Table 2. Biomass storage requirements

\begin{tabular}{|c|c|c|c|c|c|c|c|}
\hline \multirow[b]{2}{*}{ Parameters } & \multirow[b]{2}{*}{ Units } & \multicolumn{6}{|c|}{ Co-firing scenario } \\
\hline & & $5 \%$ & $10 \%$ & $20 \%$ & $50 \%$ & $70 \%$ & $100 \%$ \\
\hline Cycle inventory quantity & $\mathrm{t}$ & 26758.98 & 25955.46 & 24343.23 & 19516.93 & 16297.66 & 11471.36 \\
\hline Safety inventory quantity & $\mathrm{t}$ & 937.44 & 1874.88 & 3755.80 & 9386.49 & 13142.30 & 18772.99 \\
\hline \multirow{2}{*}{$\begin{array}{l}\text { Total maximum raw biomass } \\
\text { inventory on-site }\end{array}$} & $\mathrm{t}$ & 27696.42 & 27830.34 & 28099.04 & 28903.42 & 29439.97 & 30244.35 \\
\hline & $\mathrm{m}^{3}$ & 56523.30 & 56796.61 & 57344.98 & 58986.58 & 60081.57 & 61723.17 \\
\hline Storage area required & $\mathrm{m}^{2}$ & 9420.55 & 9466.10 & 9557.49 & 9831.09 & 10013.59 & 10287.19 \\
\hline
\end{tabular}

\subsection{Torrefaction and energy conversion system process modelling}

The studied torrefaction based co-firing system is based on a $220 \mathrm{MWe}$ coal-fired power generation unit. There are 24 burners in total located in the front wall of the boiler equally located in 4 rows. The boiler thermal input is kept in all cases at levels equal to the coal-only case for $200 \mathrm{MWe}$ output and the excess air ratio is kept at 1.15; the main steam production of $581.4 \mathrm{t} / \mathrm{h}$ at $14.15 \mathrm{MPa}$ and $538^{\circ} \mathrm{C}$ is maintained.

The overall process is modeled using Aspen Plus v7.3. In the combustion process, the biomass drying, torrefaction, milling and combustion, coal milling and combustion are all considered. All thermal processes are governed by kinetics and energy consumptions for mills are based on the empirical equations, which are detailed in [32]. The flow chart of the whole co-firing plant is presented in Fig. 2. After drying, biomass is pretreated by torrefaction process and then grinded in the existing but separate coal-mills to produce the biomass powder, which is finally introduced into the combustion chamber for burning. The biomass and/or coal are combusted with staged air to prevent the NOx emissions, which is also considered in the process modelling. The released gases during torrefaction process are finally injected into the boiler furnace as re-burning fuel. The overfire air is injected at the final stage to ensure a complete combustion. 


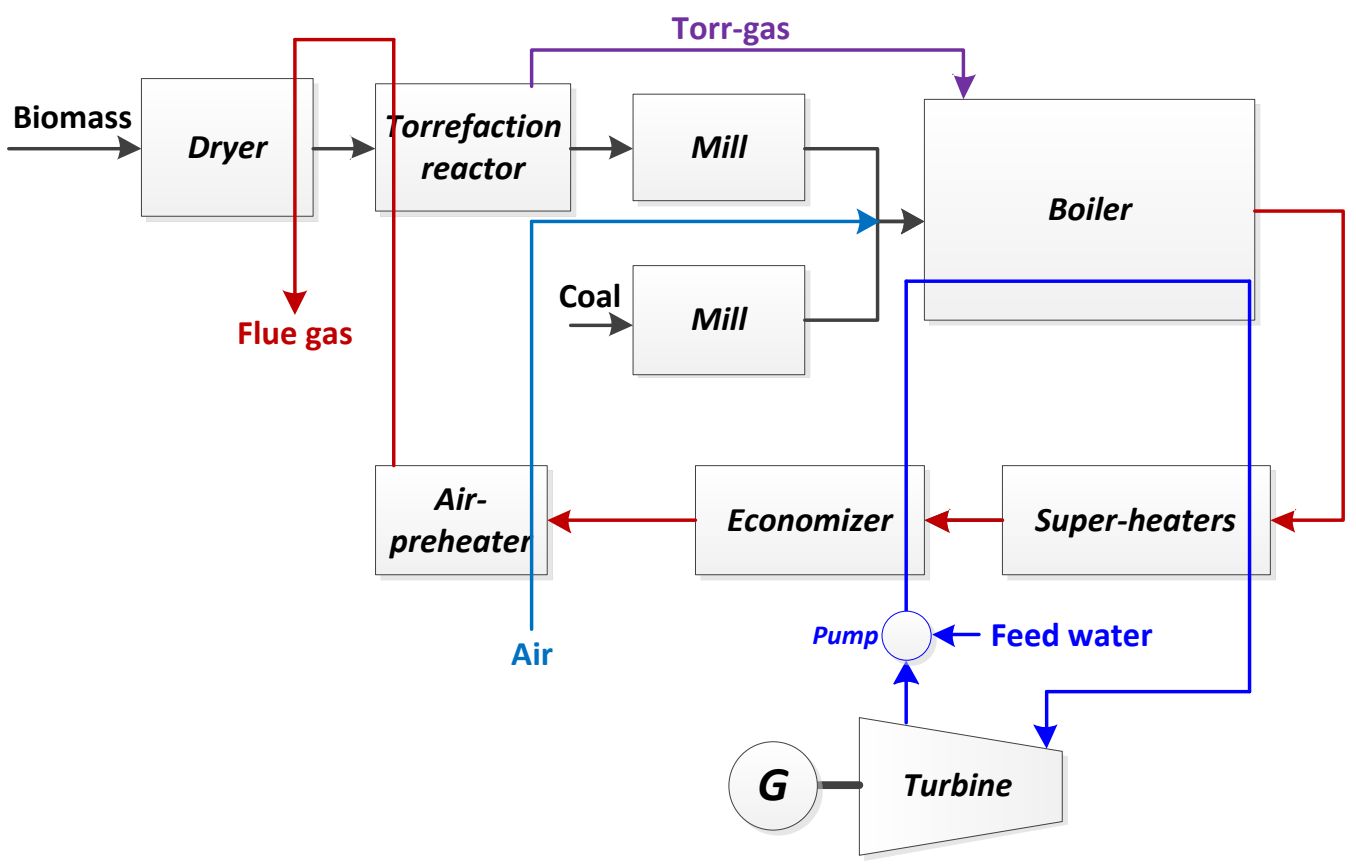

Figure 2. The flow chart of the co-firing plant with integrated biomass torrefaction

The heat exchangers and steam turbine system are also simulated, including the water wall and heat exchangers located in the backpass of the boiler that include 3-stage Super-heaters, 2-stage Attemperators, Economizer, and Air-preheater. The heat transfer from flue gas to steam and followed by the steam turbines is iteratively calculated to get converged results. Further details on the specific models can be found in [32].

For the co-firing cases, the biomass and coal are burnt separately in different burners. To figure out the performance of co-firing torrefied biomass in the front-wall pulverized coal boiler, seven different scenarios were simulated: coal only, co-firing $5 \%, 10 \%, 20 \%, 50 \%, 70 \%$ and $100 \%$ biomass on thermal basis. The proximate and ultimate parameters of PKS biomass and coal are presented in Table 3.

Table 3. Fuel properties

\begin{tabular}{|c|c|c|c|c|c|c|c|c|c|}
\hline & \multicolumn{4}{|c|}{ Proximate analysis, wt\% } & \multicolumn{4}{|c|}{ Ultimate analysis, wt\% } & \multirow{2}{*}{$\begin{array}{l}L H V^{d b} \\
(\mathrm{~kJ} / \mathrm{kg})\end{array}$} \\
\hline & Moisture $^{a r}$ & Volatile $^{a r}$ & $F C^{a r}$ & $A s h^{a r}$ & $C^{d b}$ & $H^{d b}$ & $O^{d b}$ & $N^{d b}$ & \\
\hline Biomass & 13.2 & 65.10 & 17.86 & 3.84 & 51.83 & 6.28 & 37.03 & 0.44 & 16520 \\
\hline Coal & 1.43 & 27.45 & 46.42 & 24.70 & 60.26 & 3.97 & 8.33 & 1.27 & 23303 \\
\hline
\end{tabular}

The pure coal case has been selected as the baseline case for validation and preparation of operating conditions of the co-firing cases. The coal and biomass feed rates in the various co-firing scenarios are calculated according to the equal thermal input of the coal-only case at $200 \mathrm{MWe}$. The operating conditions in the studied scenarios and the resulting electrical efficiency of the power plant are presented in Table 4. 
Table 4. Mass balance, energy balance and temperatures of the studied scenarios

\begin{tabular}{|c|c|c|c|c|c|c|c|}
\hline \multicolumn{8}{|c|}{ Mass balance } \\
\hline \multirow{2}{*}{$\begin{array}{l}\text { Biomass } \\
\text { co-firing } \\
\text { ratio (\%) }\end{array}$} & \multicolumn{3}{|c|}{ In } & \multicolumn{3}{|c|}{ Out } & \multirow[b]{2}{*}{ Overall } \\
\hline & $\begin{array}{c}\text { Biomass } \\
\left(\mathrm{kg} / \mathrm{s} /{ }^{\circ} \mathrm{C}\right)\end{array}$ & $\begin{array}{c}\text { Coal } \\
\left(\mathrm{kg} / \mathrm{s} /{ }^{\circ} \mathrm{C}\right)\end{array}$ & $\begin{array}{c}\text { Air } \\
\left(\mathrm{kg} / \mathrm{s} /{ }^{\circ} \mathrm{C}\right)\end{array}$ & $\begin{array}{c}\text { Exhaust gas } \\
\left(\mathrm{kg} / \mathrm{s} /{ }^{\circ} \mathrm{C}\right)\end{array}$ & $\begin{array}{l}\text { Ash/dust } \\
\left(\mathrm{kg} / \mathrm{s} /{ }^{\circ} \mathrm{C}\right)\end{array}$ & $\begin{array}{l}\text { Moisture }{ }^{1} \\
\left(\mathrm{~kg} / \mathrm{s} /{ }^{\circ} \mathrm{C}\right)\end{array}$ & \\
\hline 0 & - & $22.01 / 25$ & $198.97 / 25$ & $215.54 / 142$ & $5.44 / 142$ & - & \\
\hline 5 & $1.55 / 25$ & $20.91 / 25$ & 199.12 / 25 & $216.15 / 143$ & $5.22 / 143$ & $0.20 / 105$ & \\
\hline 10 & $3.10 / 25$ & $19.81 / 25$ & $199.26 / 25$ & $216.68 / 139$ & $5.08 / 139$ & $0.41 / 105$ & \\
\hline 20 & $6.21 / 25$ & $17.61 / 25$ & $199.55 / 25$ & $217.83 / 144$ & $4.72 / 144$ & $0.82 / 105$ & $m_{\text {in }}=m_{\text {out }}$ \\
\hline 50 & $15.52 / 25$ & $11.00 / 25$ & $200.43 / 25$ & $221.25 / 141$ & 3.65 / 141 & $2.05 / 105$ & \\
\hline 70 & $21.73 / 25$ & $6.60 / 25$ & $201.01 / 25$ & $223.54 / 142$ & $2.93 / 142$ & $2.87 / 105$ & \\
\hline 100 & $31.04 / 25$ & - & $201.88 / 25$ & $226.97 / 136$ & $1.86 / 136$ & $4.10 / 105$ & \\
\hline \multicolumn{8}{|c|}{ Energy balance } \\
\hline \multirow{2}{*}{$\begin{array}{l}\text { Biomass } \\
\text { co-firing } \\
\text { ratio (\%) }\end{array}$} & \multicolumn{2}{|c|}{ Energy inputs } & Generated & \multicolumn{3}{|c|}{ Auxiliary power } & \\
\hline & $\begin{array}{c}\text { Biomass } \\
(\mathrm{kW})\end{array}$ & $\begin{array}{l}\text { Coal } \\
\text { (kW) }\end{array}$ & $\begin{array}{c}\text { power } \\
(\mathrm{kW})\end{array}$ & $\begin{array}{l}\text { Pumps } \\
\text { (kW) }\end{array}$ & $\begin{array}{l}\text { Mills } \\
(k W)\end{array}$ & $\begin{array}{c}\text { Air fans } \\
(\mathrm{kW})\end{array}$ & $\begin{array}{l}\text { Electrical } \\
\text { efficiency }\end{array}$ \\
\hline 0 & 0 & 512821 & 208386 & -6457 & -1274 & -1231 & $38.74 \%$ \\
\hline 5 & 25641 & 487179 & 207934 & -6443 & -1266 & -1235 & $38.63 \%$ \\
\hline 10 & 51282 & 461538 & 205674 & -6373 & -1259 & -1232 & $38.18 \%$ \\
\hline 20 & 102564 & 410256 & 202283 & -6268 & -1243 & -1241 & $37.49 \%$ \\
\hline 50 & 256410 & 256410 & 193243 & -5988 & -1197 & -1240 & $35.64 \%$ \\
\hline 70 & 358974 & 153846 & 185332 & -5742 & -1166 & -1257 & $34.04 \%$ \\
\hline 100 & 512821 & 0 & 174484 & -5406 & -1120 & -1259 & $31.85 \%$ \\
\hline
\end{tabular}

Note: ${ }^{1}$ refers to the moisture released during the biomass drying process

\subsection{Emissions}

The GHG emission sources to be considered within the project boundary were based on the ACM0020 UNFCCC guidelines for biomass co-firing for electricity generation [33]. The guidelines provide a rationale for selecting the most important emission sources within the project boundary. According to the guidelines, the GHG emissions included in the baseline scenario are the $\mathrm{CO}_{2}$ released from fossil fuel electricity generation, whereas other GHG as well as all emissions from uncontrolled burning or decay of surplus biomass residues are not considered. Emission sources of the studied biomass co-firing scenarios include $\mathrm{CO}_{2}$ emissions from the onsite fossil fuel consumption due to biomass operations and the off-site transportation of biomass residues. Other GHG emissions as well as storage of biomass and potential wastewater from biomass treatment are excluded. Therefore, all the on-site and off-site logistical operations for the biomass supply chain have been considered in terms of their $\mathrm{CO}_{2}$ emissions in this work.

The $\mathrm{CO}_{2}$ emissions reduction achieved with each co-firing scenario is calculated by comparing the actual remaining coal emissions when co-firing with a baseline scenario that considers the emissions from a coal-only operation to generate the actual amount of electricity output of each co-firing scenario, to take into account the effect of the power plant de-rating. From the above outcome, all $\mathrm{CO}_{2}$ emissions for the logistical operations are subtracted to come up with the net $\mathrm{CO}_{2}$ emissions reduction. 


\subsection{Investment analysis}

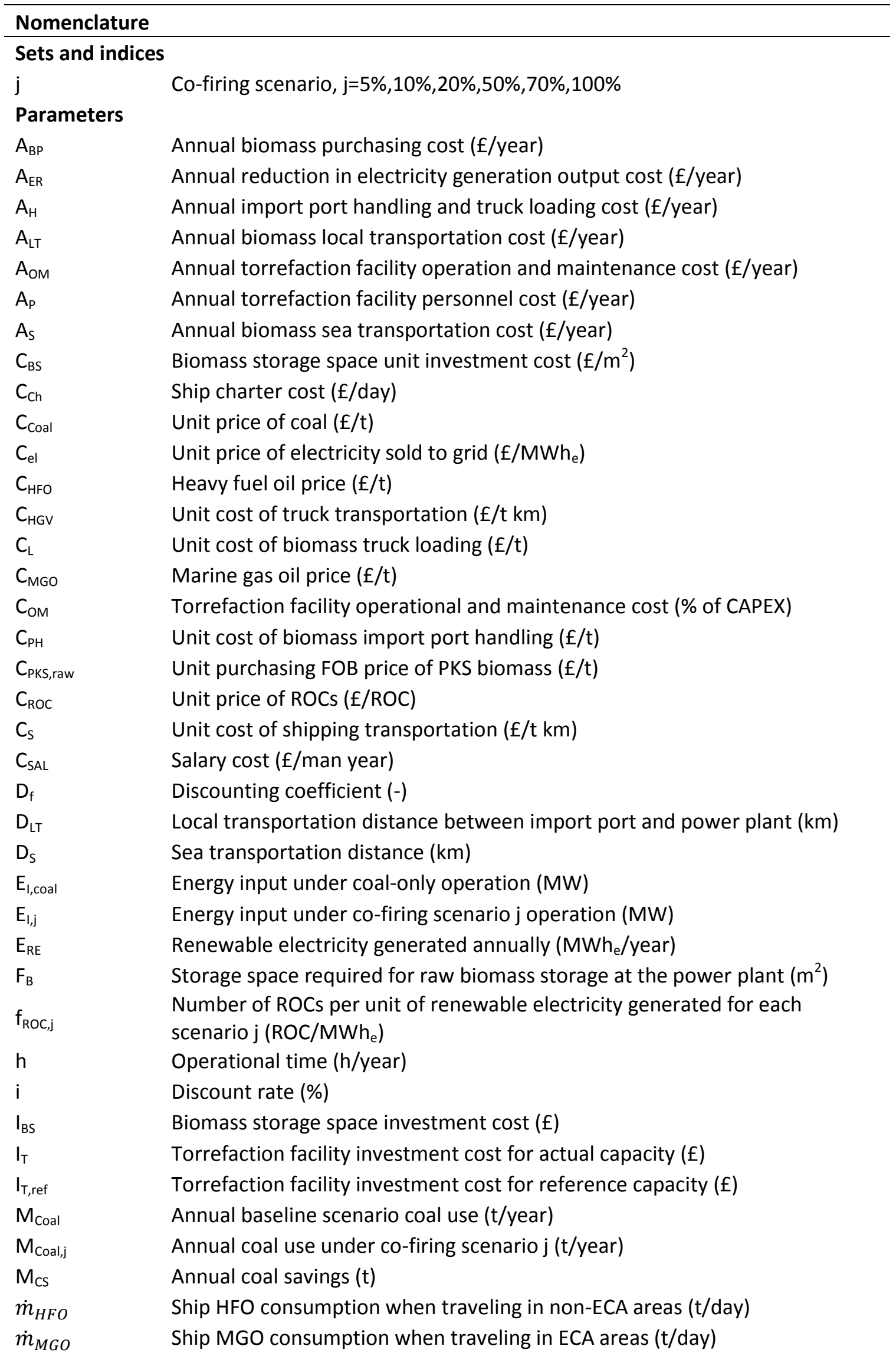




\begin{tabular}{ll}
$\dot{m}_{M G O, P}$ & Ship MGO consumption when in port (t/day) \\
$M_{\text {PKS,raw }}$ & Annual raw biomass quantity required (t/year) \\
$\mathrm{n}$ & Investment lifetime (years) \\
$\mathrm{n}_{\text {coal }}$ & Efficiency factor of power plant under coal-only operation (\%) \\
$\mathrm{n}_{\mathrm{j}}$ & Efficiency factor of power plant under co-firing scenario $\mathrm{j}$ operation (\%) \\
$\mathrm{N}_{\mathrm{P}, \mathrm{j}}$ & Personnel requirement for each scenario $\mathrm{j}$ (employees) \\
$\mathrm{P}$ & Port and canal fees for shipping ( $\mathrm{f} /$ trip) \\
$\mathrm{R}$ & Scale factor (-) \\
$\mathrm{R}_{\mathrm{C}}$ & Annual savings from reduced use of coal ( $\mathrm{f} /$ year) \\
$\mathrm{R}_{\mathrm{ROC}}$ & Annual revenues for trading green certificates ( $\mathrm{f} /$ year) \\
$\mathrm{S}_{\mathrm{CAP}}$ & Ship carrying capacity (t) \\
$\mathrm{T}_{\text {trE }}$ & Time ship is spending traveling in ECAS areas (days/trip) \\
$\mathrm{T}_{\text {trNE }}$ & Time ship is spending traveling in non-ECAS areas (days/trip) \\
$\mathrm{T}_{\mathrm{P}}$ & Time ship is spending in port (days/trip) \\
\hline
\end{tabular}

The investment analysis is performed on a differential analysis basis, by considering the differences between the required investment and resulting cash flows of the proposed co-firing scenarios with the baseline scenario, i.e. the current coal-only operation. Therefore, only changes to the existing system are taken into account in the investment analysis, whereas sunk costs and resources that are reallocated within the boundaries of the system examined while their cost remains the same between the baseline and the examined scenarios are not considered.

Annual cash flows are calculated by subtracting all operational expenses from revenues at an annual basis. The investment analysis indicators used are the Net Present Value (NPV) and Profitability Index (PI). The Internal Rate of Return (IRR), as a commonly used investment analysis criterion, is presented only for scenarios with positive NPV. The profitability index has been used in parallel to the NPV criterion to allow easier comparison of the various co-firing ratio scenarios, as the investment required can vary significantly. More specifically, the NPV is calculated as:

$N P V=\left(R_{C}+R_{R O C}\right) D_{f}-\left(I_{T}+I_{B S}\right)-\left(A_{B P}+A_{S}+A_{H}+A_{L T}+A_{E R}+A_{P}+A_{O M}\right) D_{f}$

where $D_{f}$ is the discounting coefficient, $i$ the discount rate and $n$ the investment lifetime:

$D_{f}=\frac{(1+i)^{n}-1}{i(1+i)^{n}}$

The PI is calculated as [34]:

$P I=\frac{\left(R_{C}+R_{R O C}\right) D_{f}-\left(A_{B P}+A_{S}+A_{H}+A_{L T}+A_{E R}+A_{P}+A_{O M}\right) D_{f}}{\left(I_{T}+I_{B S}\right)}$

All cost data adapted from the literature has been adjusted to 2014 values using the appropriate indexes, as this was the last year with full data availability at the time of writing.

\subsubsection{Revenues}

The system examined has two main sources of revenues. The first one is direct savings from reduced use of coal that is displaced by biomass: 
$R_{C}=M_{C S} C_{\text {Coal }}$

where $\mathrm{M}_{\mathrm{CS}}$ is the annual reduction in coal use and $\mathrm{C}_{\text {coal }}$ the unit price of coal.

The second one is revenues for trading the green certificates obtained from generating renewable electricity using biomass through co-firing $\left(R_{R O C}\right)$. In the UK, biomass use in electricity generation has been supported during the past years through the mechanism of Renewable Obligation Certificates (ROCs). ROCs are green certificates issued to operators of accredited renewable generating stations for the eligible renewable electricity they generate $\left(E_{R E}\right)$. Operators can trade ROCs with other parties at the market price $\left(\mathrm{C}_{\mathrm{ROC}}\right)$. The demand for ROCs is created by imposing specific levels of obligations to electricity suppliers and ROCs are ultimately used by suppliers to demonstrate that they have met their obligation [35]. There exists a maximum price (buy-out price) that ROCs can achieve. This is the current support mechanism for biomass co-firing and is open for new installations until the year 2017, providing ROCs in eligible operators for a duration of 20 years. Different co-firing ratios result to different number of ROCs per unit of renewable electricity generated $\left(f_{R O C, j}\right)$, for the case of electricity-only production (i.e. not Combined Heat and Power): the rates, which are also considered in this work, are 0.5 ROCs/MWh Renewable Energy for low range co-firing (less than 50\%); 0.6 ROCs/MWh for mid-range co-firing (at least 50\% and less than $85 \%$ ); and 0.9 ROCs/MWh for high-range co-firing (85\% and above) [35]:

$R_{R O C}=E_{R E} C_{R O C} f_{R O C, j}$

\subsubsection{CAPEX}

The main capital expenditure (CAPEX) in the system examined is the torrefaction facility to be built at the coal power plant. The capital expenditure cost has been adapted from [19]. To adapt the costs of the stand-alone torrefaction plant of [19] to the case examined in this work, several equipment categories relating to redundant processes have been removed: the steam boiler, as heat will be provided by the coal power plant; pelletising, cooling and milling, as in this work torrefied biomass is not pelletised and existing coal mills are assumed to be used for milling biomass [15]; and the outdoor storage is removed and substituted by the analytical calculations for raw PKS storage space to match the requirements of the particular case examined. The capital expenditure in this case has been adjusted to year 2014 prices using the yearly averaged Producer Prices in Industry Index [36]. The investment costs presented refer to a reference capacity of $200 \mathrm{kt}_{\mathrm{DS}} /$ year torrefied biomass $\left(I_{T, \text { ref }}\right)$. For torrefaction units of different nameplate capacity $\left(I_{T}\right)$, the investment cost has been approximated using the scaling function:

$I_{T}=I_{T, r e f}(\text { Size/Size ref })^{\mathrm{R}}$

where $\mathrm{R}$ is the scale factor. In this work a scale factor of 0.7 is adopted, which is the most commonly adopted for torrefaction units in the literature $[8,17,19,37]$.

The second type of capital expenditure required is for the raw PKS storage area of size $F_{B}$ (see Table 2) with unit cost $C_{B S}$ :

$I_{B S}=F_{B} C_{B S}$ 


\subsubsection{OPEX}

The operational expenditure (OPEX) for the torrefaction facility includes personnel cost, various operational and maintenance (O\&M), as well as electricity production reduction of the whole power plant.

Personnel requirement for the torrefaction facility of each co-firing scenario $\left(\mathrm{N}_{\mathrm{p}, \mathrm{j}}\right)$ has been adapted from [19], where the authors have come up with an estimation of personnel requirement for different production capacities in stand-alone torrefaction facilities. In this work, it is assumed that only $50 \%$ of the above personnel requirement will be needed, as resources that will be made available due to reduction in coal processing needs will be reallocated to the torrefaction processes and further resources can be pooled from the main power plant due to co-location of the two facilities. The annual personnel cost, assuming a yearly personnel salary cost per employee of $C_{\text {sal }}$ is:

$A_{P}=N_{P, j} C_{S a l}$

Annual operation and maintenance costs have been drawn from the literature [19], as a fixed percentage $\left(\mathrm{C}_{\mathrm{OM}}\right)$ of the torrefaction facility CAPEX:

$$
A_{O M}=I_{T} C_{O M}
$$

The reduction in electricity generation output cost $\left(A_{E R}\right)$ due to de-rating of the power plant that results from co-firing biomass has also been considered as an expense to the system, as ultimately the income of the whole power plant will be affected by this reduction:

$A_{E R}=\left(n_{\text {Coal }} E_{I, \text { coal }}-n_{j} E_{I, j}\right) h C_{e l}$

where $\mathrm{n}_{\text {coal }}$ and $\mathrm{n}_{\mathrm{j}}$ are the efficiency factors of the power plant under coal-only and co-firing scenario $j, E_{1, c o a l}$ and $E_{1, j}$ the respective energy inputs, $h$ the annual operational time and $C_{e l}$ the unit price of electricity.

The operational expenditure relating to the biomass supply chain is added to the torrefaction unit operational expenditure to calculate the total yearly expenditure. The biomass supply chain costs are calculated by adding the biomass purchasing cost delivered at the export port in Malaysia, the sea transportation cost, which includes the loading to vessel cost using the vessel equipment, handling at the import port, loading to trucks, and local transportation costs from import port to the power plant. The last three stages are only accounted in terms of cost for the excess amount of feedstock handled yearly in comparison to the baseline scenario, as biomass displaces coal at cofiring scenarios and the handling and local transportation resources allocated originally to coal will partially cover the logistical requirements of the biomass.

More specifically, the annual biomass purchasing cost $\left(A_{B P}\right)$ is calculated by multiplying the annual raw biomass quantity required $\left(\mathrm{M}_{\mathrm{PKS}, \text { raw }}\right)$ by the unit price $\left(\mathrm{C}_{\mathrm{PKS}, \text { raw }}\right)$ :

$A_{B P}=M_{P K S, r a w} C_{P K S, \text { raw }}$

The annual sea transportation cost $\left(A_{s}\right)$ is:

$A_{S}=M_{P K S, \text { raw }} D_{S} C_{S}$ 
where $D_{S}$ is the transportation distance and $C_{S}$ the unit sea transportation cost calculated as:

$C_{S}=\frac{\left(C_{C h}\left(T_{t r E}+T_{t r N E}+T_{P}\right)+C_{H F O} \dot{m}_{H F O} T_{t r N E}+C_{M G O} \dot{m}_{M G O} T_{t r E}+C_{M G O} \dot{m}_{M G O, P} T_{P}+P\right.}{D_{S} S_{C A P}}$

where $C_{c h}$ is the daily ship chartering cost, $C_{H F O}$ and $C_{M F O}$ are the unit prices of the respective fuels, $T_{\text {trE, }}, T_{\text {trNE }}$ and $T_{P}$ the time the ship is spending traveling in ECA, non-ECA areas and at port (loading and unloading) respectively, $\mathrm{P}$ the port and canal fees. $\dot{m}_{H F O}, \dot{m}_{M G O}, \dot{m}_{M G O, P}$ are the fuel consumption per unit of time when traveling in non-ECA, ECA areas and when loading and unloading at ports. $\mathrm{S}_{\text {CAP }}$ is the ship carrying capacity that is determined by volume in the case examined. All the above parameters refer to a single trip.

The annual import port handling and truck loading cost $\left(A_{H}\right)$ is:

$A_{H}=\left(M_{P K S, \text { raw }}+M_{\text {Coal }, j}-M_{\text {Coal }}\right)\left(C_{P H}+C_{L}\right)$

where $C_{P H}$ is the port unloading and handling cost per unit of biomass, $C_{L}$ the truck loading cost per unit of biomass, $M_{\text {coal }}$ the baseline scenario annual coal use and $M_{\text {coal,j }}$ the coal use under co-firing scenario $j$. The annual local transportation cost of biomass using trucks $\left(A_{L T}\right)$ is:

$A_{L T}=\left(M_{P K S, r a w}+M_{C o a l, j}-M_{\text {Coal }}\right) 2 D_{L T} C_{H G V}$

where $2 \mathrm{D}_{\mathrm{LT}}$ is the return trip distance of trucks and $\mathrm{C}_{\mathrm{HGV}}$ the unit cost of truck transportation.

The main inputs for the investment analysis stage are presented in Table 5.

Table 5. Investment analysis input parameter values

\begin{tabular}{|c|c|c|c|}
\hline Main Input Parameters & Unit & Value & Source \\
\hline \multicolumn{4}{|l|}{ Financial } \\
\hline Investment lifetime & years & 15 & {$[17,19]$} \\
\hline Discount rate & $\%$ & 8 & {$[8,17,21]$} \\
\hline Salvage value after depreciation & $f$ & 0 & Assumption \\
\hline \multirow{2}{*}{ PKS price } & $f / t$ & 39.18 & Inductrucourcos \\
\hline & $f / G J$ & 2.37 & Inaustry sources \\
\hline Coal price & $f / t$ & 56.70 & [38] \\
\hline HFO price & $f / t$ & 304.80 & [39] \\
\hline MGO price & $f / t$ & 499.50 & [39] \\
\hline Reference torrefaction capacity & $\begin{array}{l}\mathrm{t} / \mathrm{h} \text { torrefied } \\
\text { biomass }\end{array}$ & 23.74 & [19] \\
\hline CAPEX Reference torrefaction capacity & $M f$ & 20.45 & $\begin{array}{l}\text { Adapted from } \\
\text { [19] }\end{array}$ \\
\hline Scale factor for torrefaction & & 0.70 & {$[8,17,19,37]$} \\
\hline Electricity Price & f/MWh & 41.76 & [40] \\
\hline ROC price & $\mathrm{f} / \mathrm{ROC}$ & 41.83 & $\begin{array}{l}\text { Average value for } \\
2014\end{array}$ \\
\hline$O \& M$ cost & $\%$ of CAPEX/year & 2 & [19] \\
\hline Workers average salary cost & f/year & 34015.06 & $\begin{array}{l}\text { Calculated from } \\
\text { [41] }\end{array}$ \\
\hline
\end{tabular}




\section{Results and discussion}

\subsection{Investment analysis results}

The investment analysis results reveal that none of the co-firing scenarios exhibits a positive NPV, apart from the $100 \%$ biomass scenario (Fig. 3). Considering the Profitability Index results in Fig. 4, where any value above 1 indicates a profitable investment, it is evident that the $100 \%$ biomass scenario is a very profitable investment and that the $50 \%$ co-firing scenario is the one of the co-firing scenarios that is closer to being profitable. The $100 \%$ biomass scenario is also found to present a very attractive IRR of $34.2 \%$.

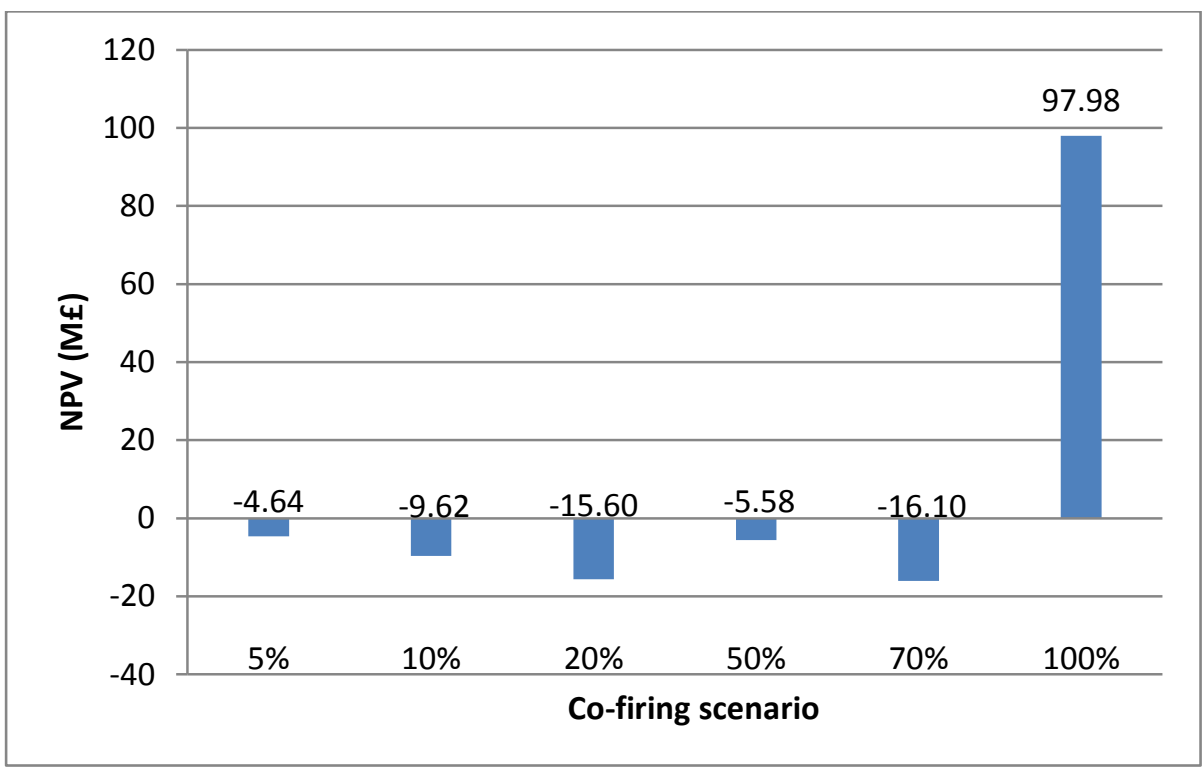

Figure 3. Net Present Value of co-firing scenarios examined

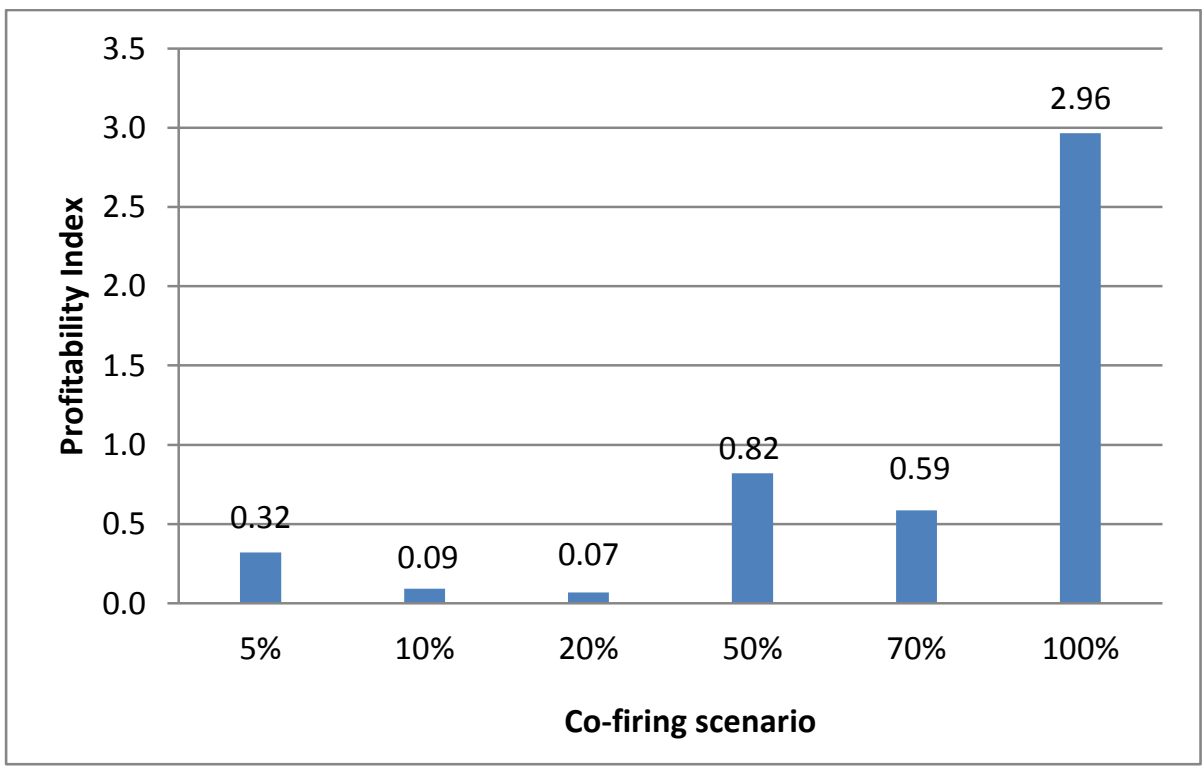

Figure 4. Profitability Index of co-firing scenarios examined 
The results indicate the effect of the current Renewable Obligations mechanism, which strongly promotes complete fuel switch of coal power plants to biomass, due to the stepwise change of the $\mathrm{ROC} / \mathrm{MWh}$ band. This finding is in line with what has actually happened in the UK during the past years, when several coal-fuelled units were completely retrofitted to dedicated biomass units, albeit not using torrefaction technology. A more detailed understanding of this phenomenon can be gained by Fig. 5, where it can be seen that the higher the co-firing ratio, the higher the percentage of revenue that originates from ROCs compared to coal use reduction savings. For low co-firing ratios, ROC income is the secondary revenue stream compared to coal savings, with ROC revenue contributing $48 \%$ of the total for the $5 \%$ co-firing scenario, but becomes the primary contributor for high co-firing ratios, contributing $58 \%$ for the $100 \%$ biomass scenario. The main reason behind this is the change in the RO banding that allocates a higher number of ROCs per MWh of renewable energy generated for higher co-firing rates.

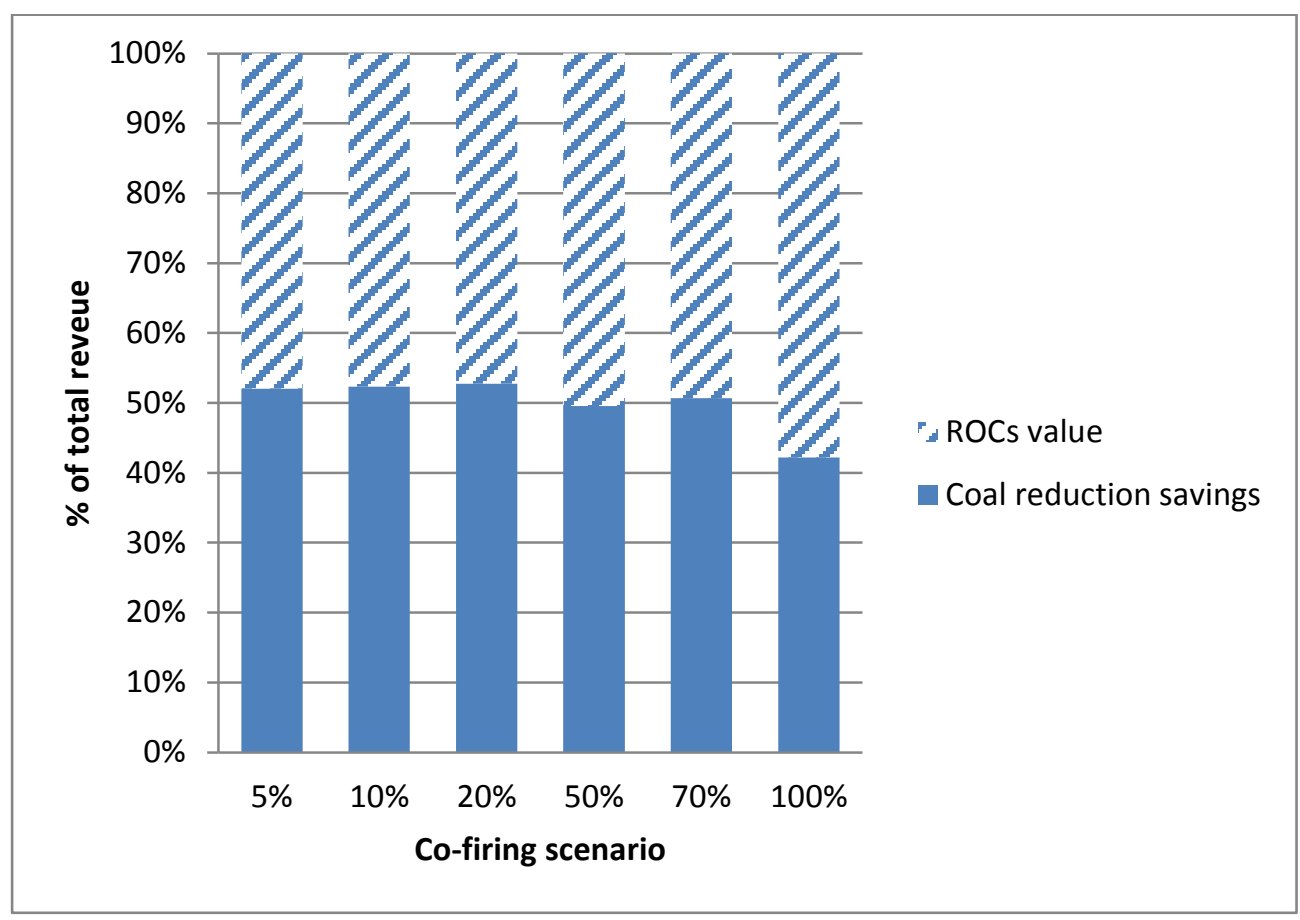

Figure 5. Breakdown of annual revenue

The expenditure breakdown indicates that significant differences exist between the main cost factors for each co-firing scenario (Fig. 6). The initial investment required for the torrefaction unit constitutes a much more significant expense stream for low co-firing ratios, with the extreme of $18.4 \%$ of the total cost for the $5 \%$ co-firing scenario and reducing to $8.2 \%$ for the $100 \%$ biomass scenario. The economies of scale in the torrefaction facility investment cost are the major contributor to this result, which, in combination with lower ROC allowance support, explains the poor financial yield of low co-firing ratio scenarios. The total investment cost, including the biomass storage space that needs to be constructed, follows a similar pattern, ranging from $21 \%$ of the total cost for the $5 \%$ co-firing scenario to $8.4 \%$ for the $100 \%$ biomass scenario. Interestingly, investment cost is a small percentage of the overall cost for high co-firing rate scenarios. 
Operational expenditure is the largest contributor to the expenses. The primary factor is the biomass purchasing cost, ranging from $43.5 \%$ of the total cost for the $5 \%$ co-firing scenario to $47.9 \%$ for the $100 \%$ biomass scenario. Therefore, securing low cost biomass sources with long-term contracts should be a major priority of investors interested at a similar investment case. As this cost is difficult to predict and could increase if biomass demand increases in the future, its effects are further analysed in the sensitivity analysis section, together with other influential parameters identified.

Sea transportation of biomass is the second most important cost factor for all scenarios, ranging from $19 \%$ of the total cost for the $5 \%$ co-firing scenario to $20.9 \%$ for the $100 \%$ biomass scenario. This indicates the importance of sea transportation in determining the overall profitability of the investment, particularly due to the very long transportation distance examined in this work.

Reduction in electricity output due to power plant de-rating results in significant income loss of up to $16.2 \%$ of total cost for scenarios with high co-firing ratio scenarios, while it is only $4.8 \%$ for the low co-firing ratio scenario.

Unloading and handling of biomass at the import port as well as local transportation lead to a similar range of cost contribution irrespective of co-firing rate and are low in absolute terms, primarily due to the assumption that only the amounts of biomass in excess of the difference between the amount of biomass import and coal reduction will be considered for the investment analysis as an additional cost to the system.

Personnel cost for the torrefaction facility is considerable for low co-firing ratios, up to $4.7 \%$ for the $5 \%$ co-firing scenario, but becomes insignificant for high co-firing ratios with a value as little as $0.8 \%$ for the $100 \%$ biomass scenario. This is a result of the economies of scale for personnel requirement with the size of the facility. Finally, the Operation and Maintenance cost is higher for low co-firing ratio scenarios, up to $3.1 \%$ of the total cost for the $5 \%$ co-firing scenario and is reduced to $1.4 \%$ for the $100 \%$ biomass scenario.

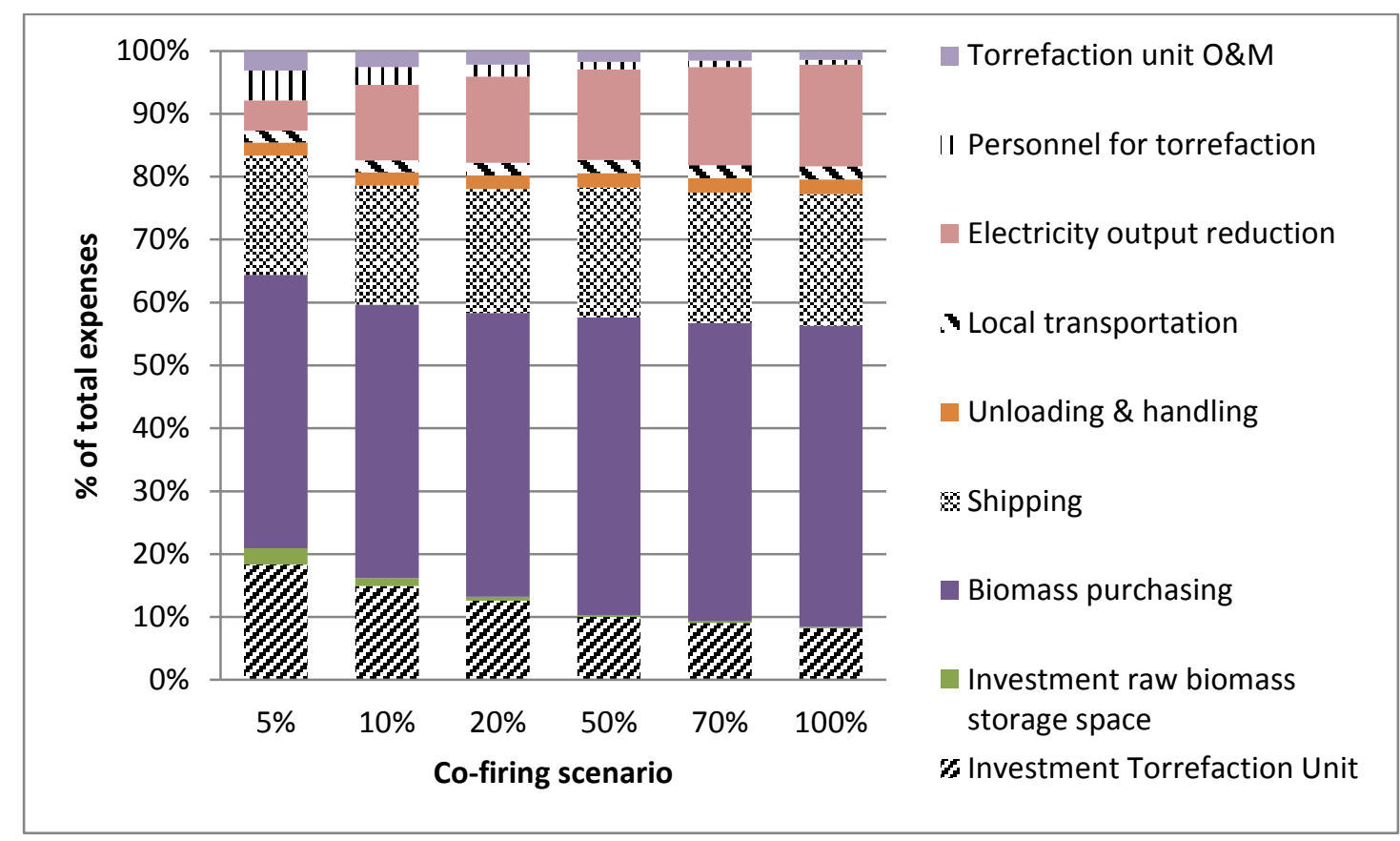

Figure 6. Breakdown of expenditure 
The cost of delivered torrefied biomass per unit of energy at the mills of the co-firing power plant has also been calculated for the scenarios examined and is presented in Table 6, to facilitate comparison between different supply chains and feedstock sources. The biomass cost has been identified by calculating the equivalent annual fixed costs relating to the required investment for the supply and torrefaction system, according to [42], and adding the annual operating costs, divided by the annual amount of torrefied feedstock produced. It is interesting to note that the delivered feedstock cost is significantly reduced for higher quantities, primarily due to the economies of scale at the torrefaction unit. It should be noted that the costing does not include the loss of income due to power plant de-rating (see Fig. 6: Electricity output reduction), which ultimately reduces the benefit from feedstock cost reduction when performing the system-wide investment analysis.

Table 6. Delivered torrefied feedstock cost at power plant mills

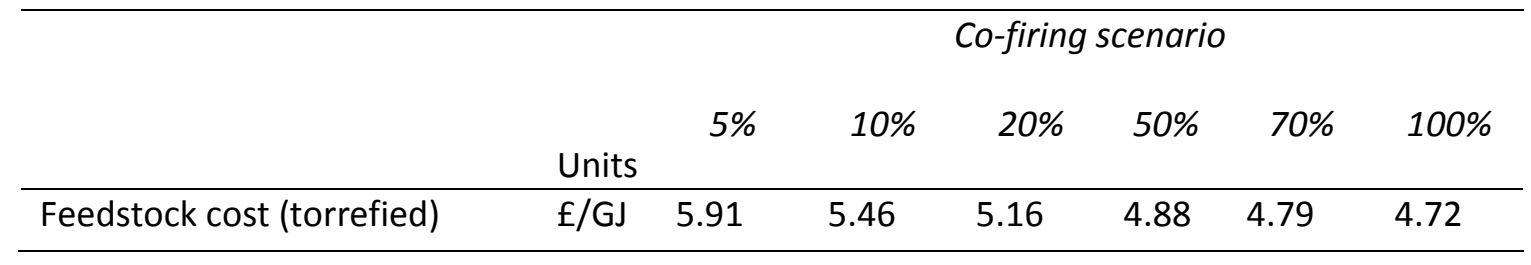

An additional analysis has been performed to identify the marginal cost of reducing $\mathrm{CO}_{2}$ emissions for each co-firing scenario. The marginal cost is of value to policy makers, as it indicates the value for each unit of actual $\mathrm{CO}_{2}$ emissions reduction achieved that would render the investment marginally profitable (i.e. leading to an NPV $=0$ ). Fig. 7 shows that the $100 \%$ biomass scenario becomes profitable with the least $\mathrm{CO}_{2}$ value, a fact aligning with the current regulatory framework that promotes higher co-firing ratios by allocating higher ROC allowances per unit of renewable energy generated. It is interesting to note, however, that the $50 \%$ co-firing rate scenario has practically the same marginal cost, but presents environmental benefits compared to the $100 \%$ biomass scenario, such as the higher efficiency factor of the system due to lower de-rating and the subsequent fact that more energy can be generated from a unit of biomass (shown in Fig. 8). Furthermore, the $5 \%$ co-firing scenario appears to have the least $\mathrm{CO}_{2}$ marginal cost from the low co-firing ratio scenarios, as the related cost is only $3.7 \%$ higher than the $100 \%$ biomass scenario. Consequently, if torrefaction systems are to be installed, it could be more effective for policy makers from a systems perspective to promote and support $50 \%$ co-firing ratios rather than complete conversion of whole units.

Furthermore, considering the fact that normally coal fired plants consist of a number of units similar to the one examined, introducing a low co-firing ratio of torrefied biomass for all the units of the plant could lead to a shared torrefaction facility similar to the largest ones examined in this work, therefore taking advantage of the economies of scale too. In this case, even promoting the $5 \%$ cofiring ratio could present an interesting and cost-effective pathway to promote biomass use from a policy makers' perspective. 


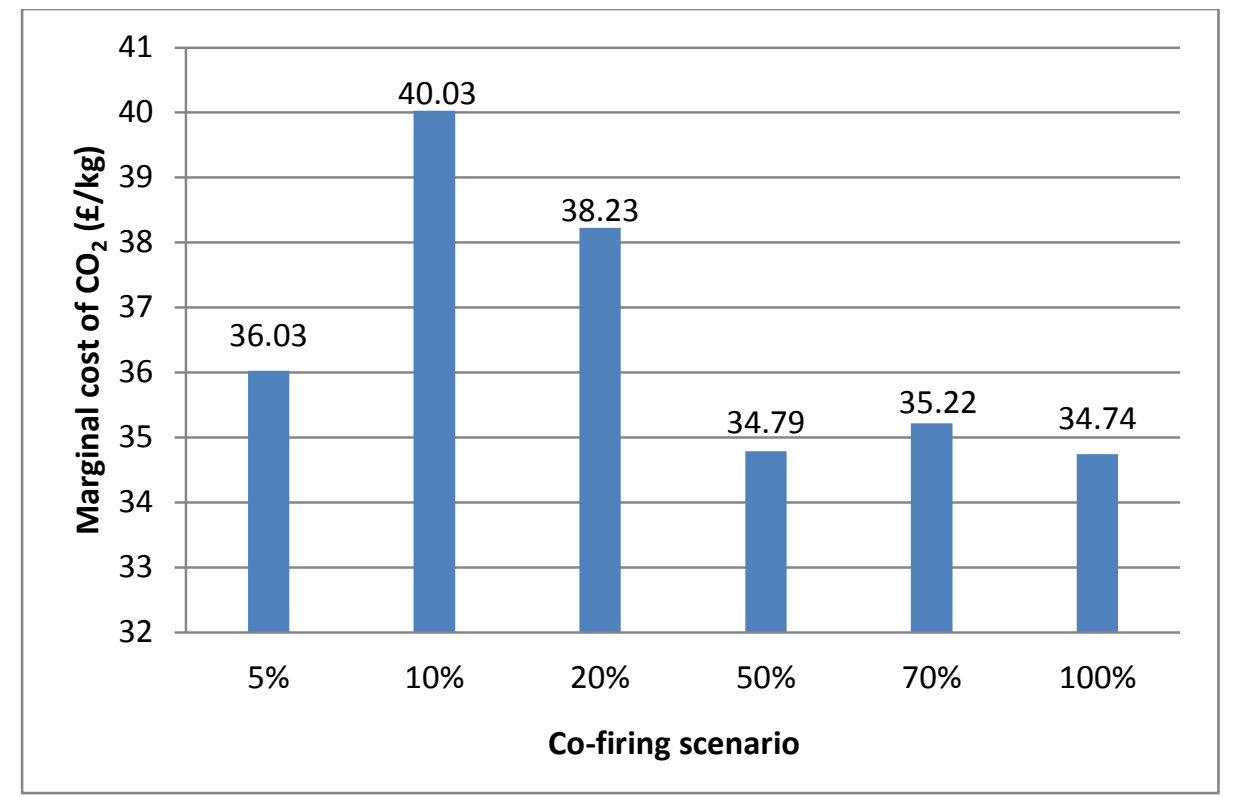

Figure 7. Marginal cost of reducing $\mathrm{CO}_{2}$ emissions

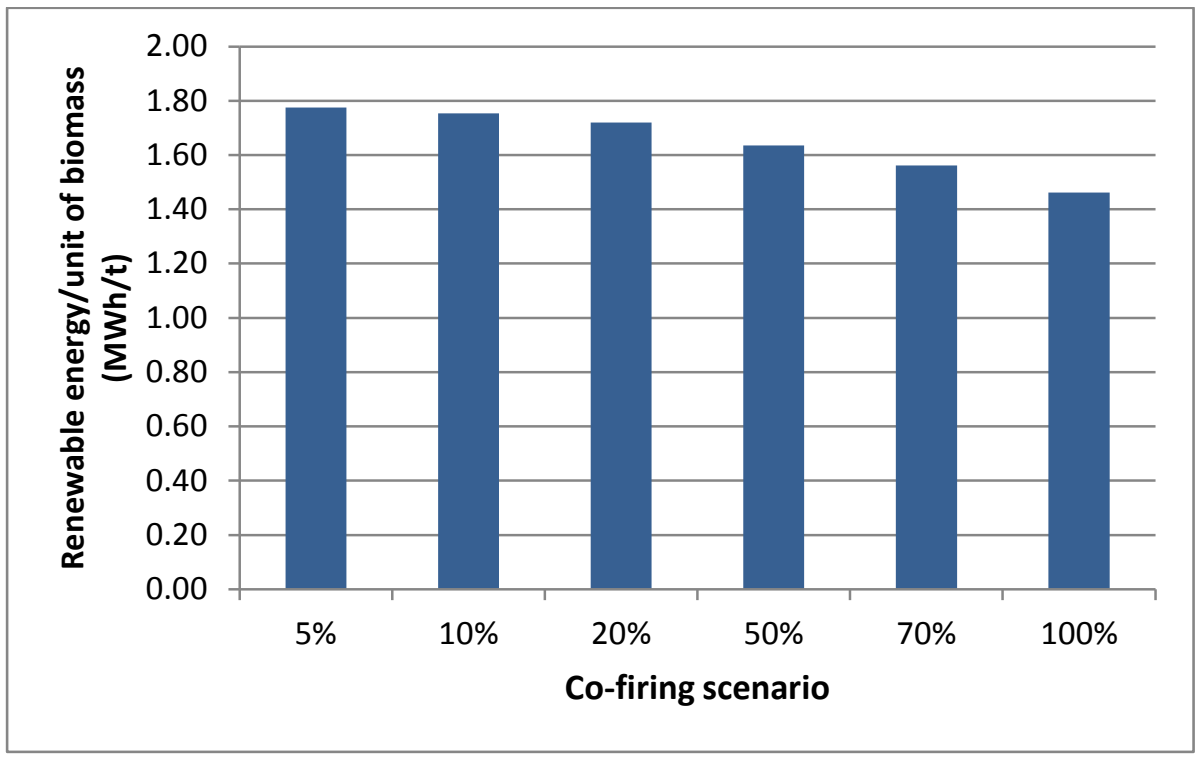

Figure 8. Renewable energy (electricity) generated per unit of biomass

\subsection{System emissions}

The total annual net $\mathrm{CO}_{2}$ emissions reduction achieved through each co-firing scenario ranges from $58.8 \mathrm{kt} \mathrm{CO}_{2}$ per year for the $5 \%$ co-firing scenario to $1015.5 \mathrm{kt} \mathrm{CO}_{2}$ per year for the $100 \%$ biomass scenario, indicating the total environmental benefit from biomass use (Fig. 9). 


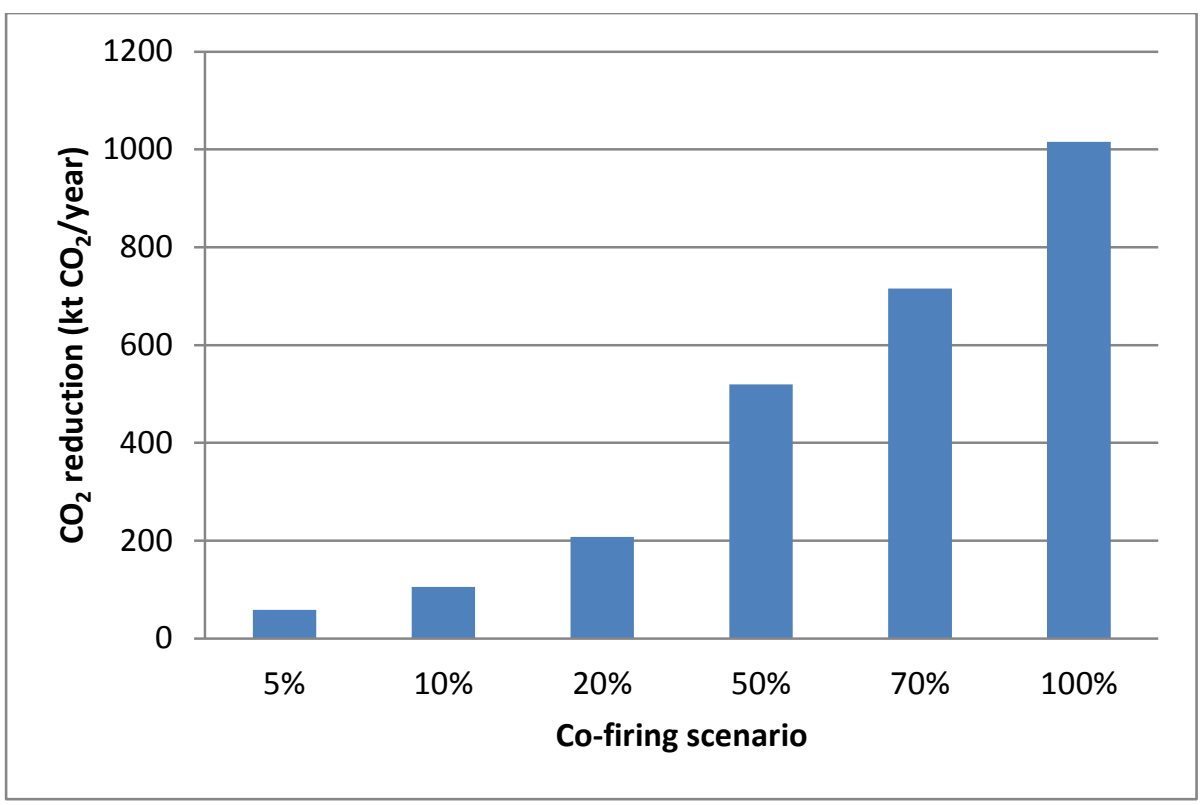

Figure 9. Total annual net $\mathrm{CO}_{2}$ emissions reduction

Transporting biomass in long distances would seem less environmentally friendly than using the biomass locally where it is produced; however, researchers have concluded that importing biomass from Malaysia and Canada to Netherlands for co-firing would lead to higher net avoided GHG emissions than for electricity/heat production in dedicated plants in the country of origin [9]. Similarly, no large differences were observed on the environmental loads between domestic use of bioenergy or export of solid biofuel from Sweden to Netherlands [43]. Therefore, past research findings suggest that biomass can be transported over long distances without losing its environmental benefits, provided that the supply system is appropriately designed.

Fig. 10 presents the $\mathrm{CO}_{2}$ emissions breakdown by supply chain stage for all the co-firing scenarios examined in this work. The downstream stages of 'unloading and handling' the biomass at the import port and 'local transportation' from the import port to the power plant have considered the total amount of biomass required to be transported, in contrast to the investment analysis section, to present a holistic view of the supply chain emissions in order for the results to be useful to other researchers. Approximately $55 \%-58 \%$ of the total supply system $\mathrm{CO}_{2}$ emissions are attributed to the sea transportation stage, despite the relatively recent slow steaming practice that is also assumed in this work, which significantly reduces emissions and fuel use. Local operations in Malaysia are the second most important emissions source, accounting for $27 \%-31 \%$ of the total. The total emissions incurred due to biomass logistics correspond to a range between $57.6 \mathrm{~kg} \mathrm{CO}_{2} / \mathrm{MWh}$ renewable electricity generated for the $5 \%$ co-firing scenario and $66.1 \mathrm{~kg} \mathrm{CO}_{2} / \mathrm{MWh}$ for the $100 \%$ biomass scenario. Interestingly, the higher biomass co-firing scenarios lead to an increased environmental impact from logistics equal to a $14.8 \% \mathrm{CO}_{2}$ emissions increase between the two extreme scenarios, primarily due to the de-rating of the power plant and the reduction of the efficiency factor, which leads to a higher fuel input demand per unit of renewable energy generated and primarily impacts sea transportation emissions. 


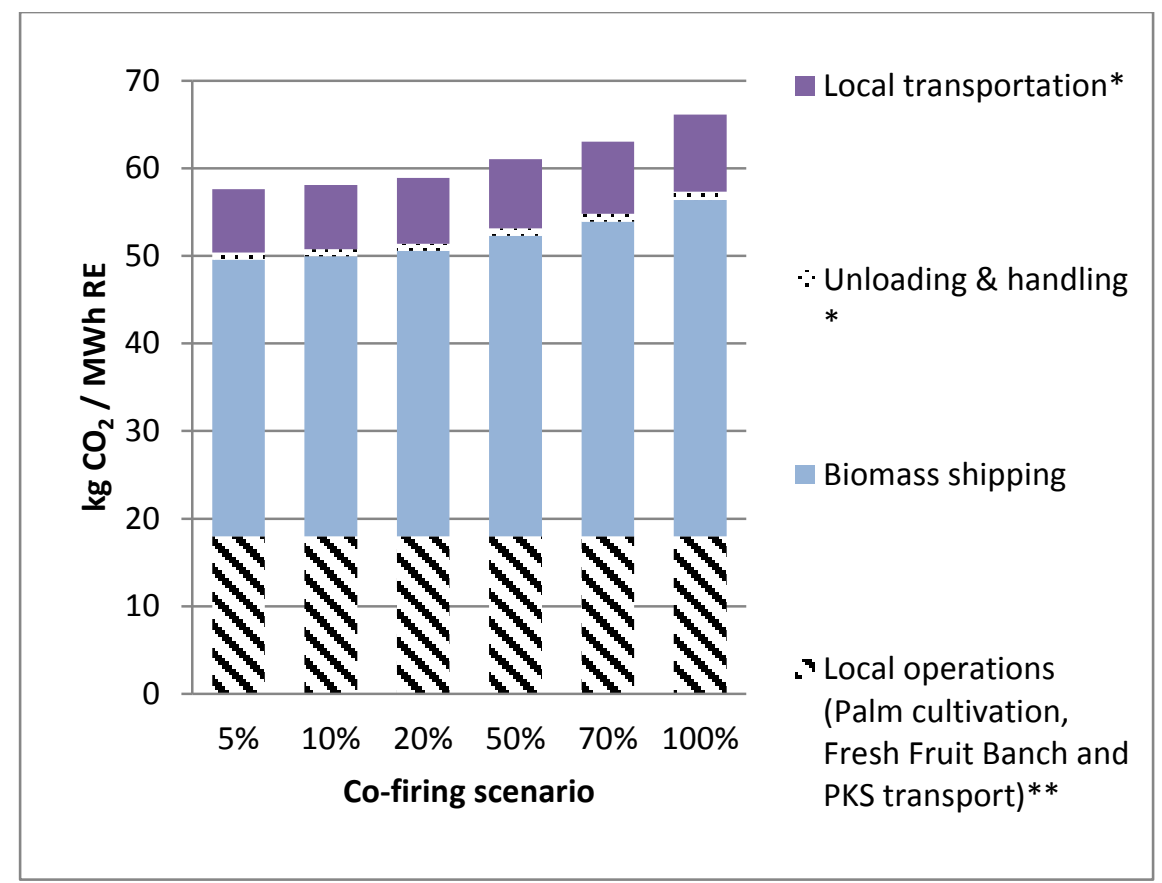

Figure 10. $\mathrm{CO}_{2}$ emissions from biomass logistics stages

* Accounts for the entire amount of biomass sourced

** Adapted from [9]

A similar conclusion can be drawn when investigating the percentage of $\mathrm{CO}_{2}$ savings from using biomass compared to coal that is actually lost due to the biomass logistics operations and the respective fossil fuel consumption. This ranges from $6.93 \%$ for the $5 \%$ co-firing scenario to $7.94 \%$ for the $100 \%$ biomass scenario, if the whole biomass amount is considered (striped bars in Fig. 11), or $6.24 \%$ to $7.16 \%$ respectively, if only the excess amount of fuel transported from the import port to the power plant is considered (solid bars in Fig. 11). Therefore, lower co-firing ratios appear to lead to increased environmental performance in terms of actual $\mathrm{CO}_{2}$ reduction, when looking at the whole renewable energy generation system.

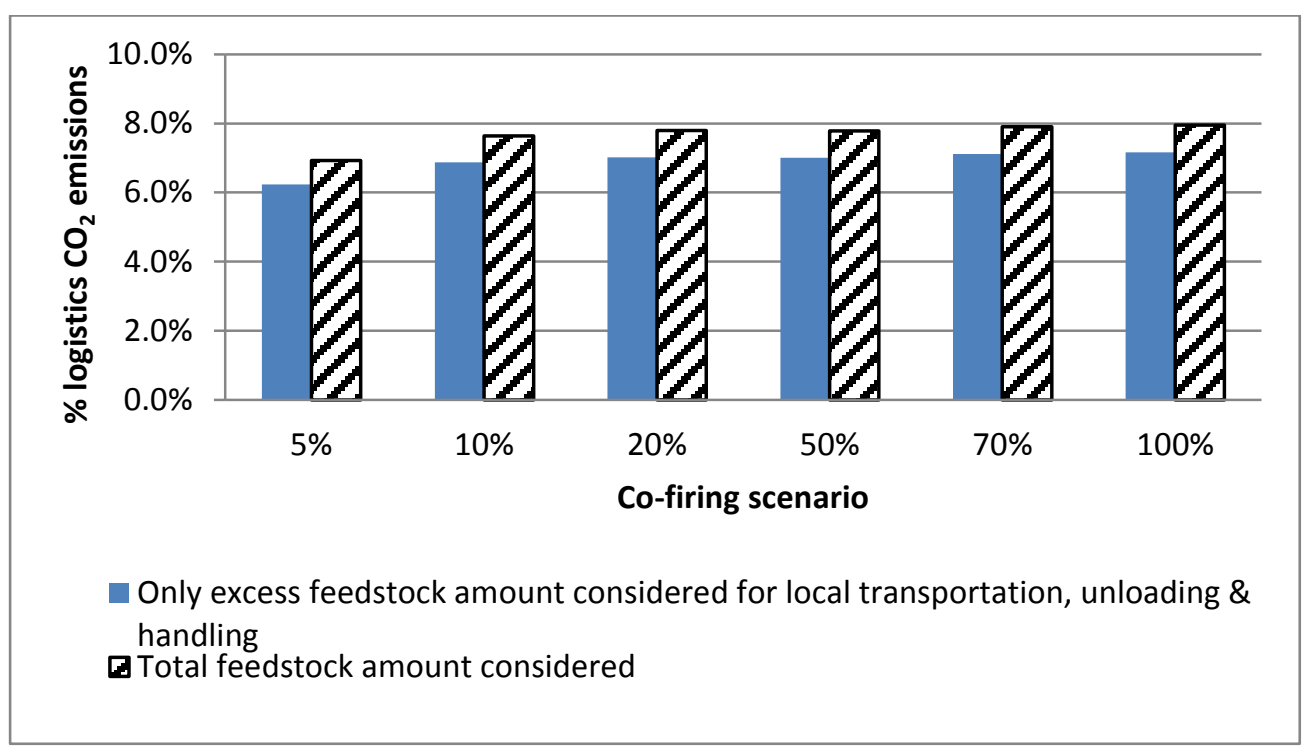

Figure 11. Logistics $\mathrm{CO}_{2}$ emissions compared to overall system $\mathrm{CO}_{2}$ savings 
The primary energy input due to the whole supply chain of PKS biomass has been calculated equal to $9.48 \%$ of the energy transported and its breakdown on each supply chain stage can be seen in Fig.

12. Sea transportation accounts for more than $54 \%$ of the energy input, as its high energy efficiency per unit of goods transported is countervailed by the long transportation distance required.

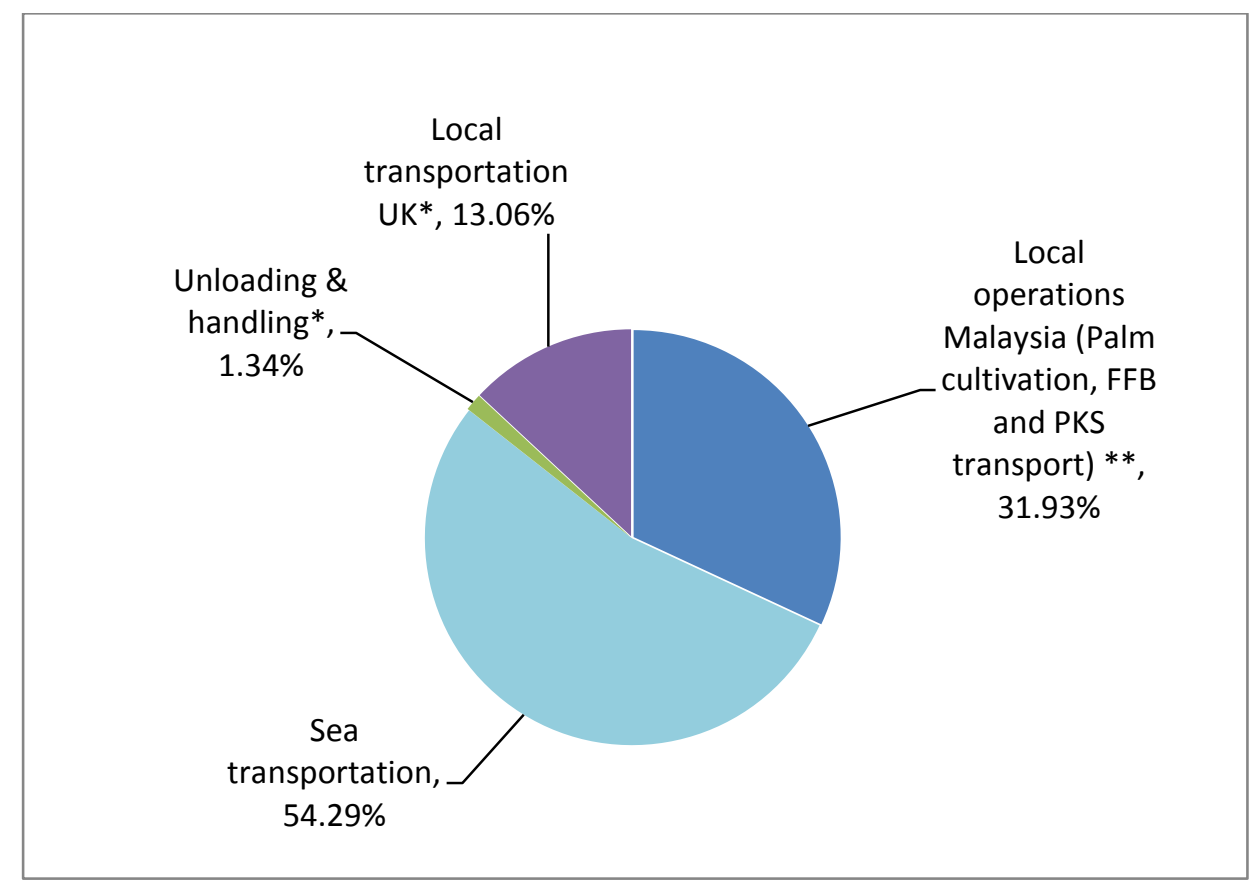

Figure 12. Primary energy use for production and logistics operations of PKS

* Accounts for the entire amount of biomass sourced

** Adapted from [9]

\section{Sensitivity analysis results}

Many of the input parameters considered in the analysis are inherently variable, as they are external to the system examined. Therefore, a sensitivity analysis of the financial yield on the change of the most influential parameters has been performed. Most parameters have been subject to a change of $-25 \%$ and $+25 \%$ of their baseline value, in accordance with other techno-economic analyses of torrefaction systems $[19,37]$. The only exceptions are the operational time and the scale factor, where such a high rate of change would not be meaningful in practical terms. All parameters examined in the sensitivity analysis, their baseline, lower and upper values are summarized in Table 7. To keep the size of the paper reasonable, only the sensitivity analysis results for the most representative scenarios are presented, i.e. co-firing $5 \%, 50 \%$ and $100 \%$ biomass. Sensitivity analysis results for the rest of the scenarios are available upon request. Profitability Index (PI) has been used as the output measure for this analysis, to facilitate cross-scenario comparison of results. To improve legibility, sensitivity analysis results for each scenario are grouped and discussed by type of parameter (Fig. 13a-c). In the sensitivity analysis charts, the point on the horizontal axis where the vertical axis crosses denotes the base case PI of each scenario. 
Table 7. Parameters and ranges of sensitivity analysis

\begin{tabular}{|c|c|c|c|c|c|c|}
\hline \multirow[b]{2}{*}{ Parameter } & \multirow[b]{2}{*}{$\begin{array}{l}\text { Baseline } \\
\text { Value }\end{array}$} & \multirow[b]{2}{*}{ Unit } & \multicolumn{4}{|c|}{ Sensitivity Analysis Range } \\
\hline & & & $\begin{array}{c}\text { Lower } \\
\text { Parameter } \\
\text { Value } \\
\end{array}$ & $\begin{array}{c}\text { Decrease } \\
\%\end{array}$ & $\begin{array}{c}\text { Upper } \\
\text { Parameter } \\
\text { Value }\end{array}$ & $\begin{array}{c}\text { Increase } \\
\%\end{array}$ \\
\hline \multicolumn{7}{|c|}{ Revenue-related parameters } \\
\hline Coal price & 56.70 & $f / t$ & 42.53 & $-25 \%$ & 70.88 & $+25 \%$ \\
\hline ROCs market value & 41.83 & f/ROC & 31.37 & $-25 \%$ & 52.29 & $+25 \%$ \\
\hline \multicolumn{7}{|c|}{ CAPEX/OPEX parameters } \\
\hline $\begin{array}{l}\text { price } \\
\text { Capital cost }\end{array}$ & 39.18 & $f / t$ & 29.39 & $-25 \%$ & 48.98 & $+25 \%$ \\
\hline reference & 20.45 & $M f$ & 15.34 & $-25 \%$ & 25.57 & $+25 \%$ \\
\hline Discount rate & 8.0 & $\%$ & $6.0 \%$ & $-25 \%$ & $10.0 \%$ & $+25 \%$ \\
\hline Electricity price & 41.76 & $\mathrm{f} / \mathrm{MWh}$ & 31.32 & $-25 \%$ & 52.20 & $+25 \%$ \\
\hline Personnel cost & 34015 & f/year & 25511 & $-25 \%$ & 42519 & $+25 \%$ \\
\hline Scale factor & 0.70 & & 0.60 & $-14 \%$ & 0.80 & $+14 \%$ \\
\hline \multicolumn{7}{|c|}{ Operational parameters } \\
\hline Operational time & 7600 & h/year & 7200 & $-5 \%$ & 8000 & $+5 \%$ \\
\hline \multicolumn{7}{|c|}{ Supply system parameters } \\
\hline Sea transport cost & 0.00107 & $\mathrm{f} / \mathrm{t} * \mathrm{~km}$ & 0.00080 & $-25 \%$ & 0.00134 & $+25 \%$ \\
\hline Road transport cost & 0.05881 & $\mathrm{f} / \mathrm{t}^{*} \mathrm{~km}$ & 0.04411 & $-25 \%$ & 0.07351 & $+25 \%$ \\
\hline Oil price (HFO) & 304.8 & $f / t$ & 228.6 & $-25 \%$ & 381.0 & $+25 \%$ \\
\hline Biomass density & 490.0 & $\mathrm{~kg} / \mathrm{m}^{3}$ & 367.5 & $-25 \%$ & 612.5 & $+25 \%$ \\
\hline
\end{tabular}




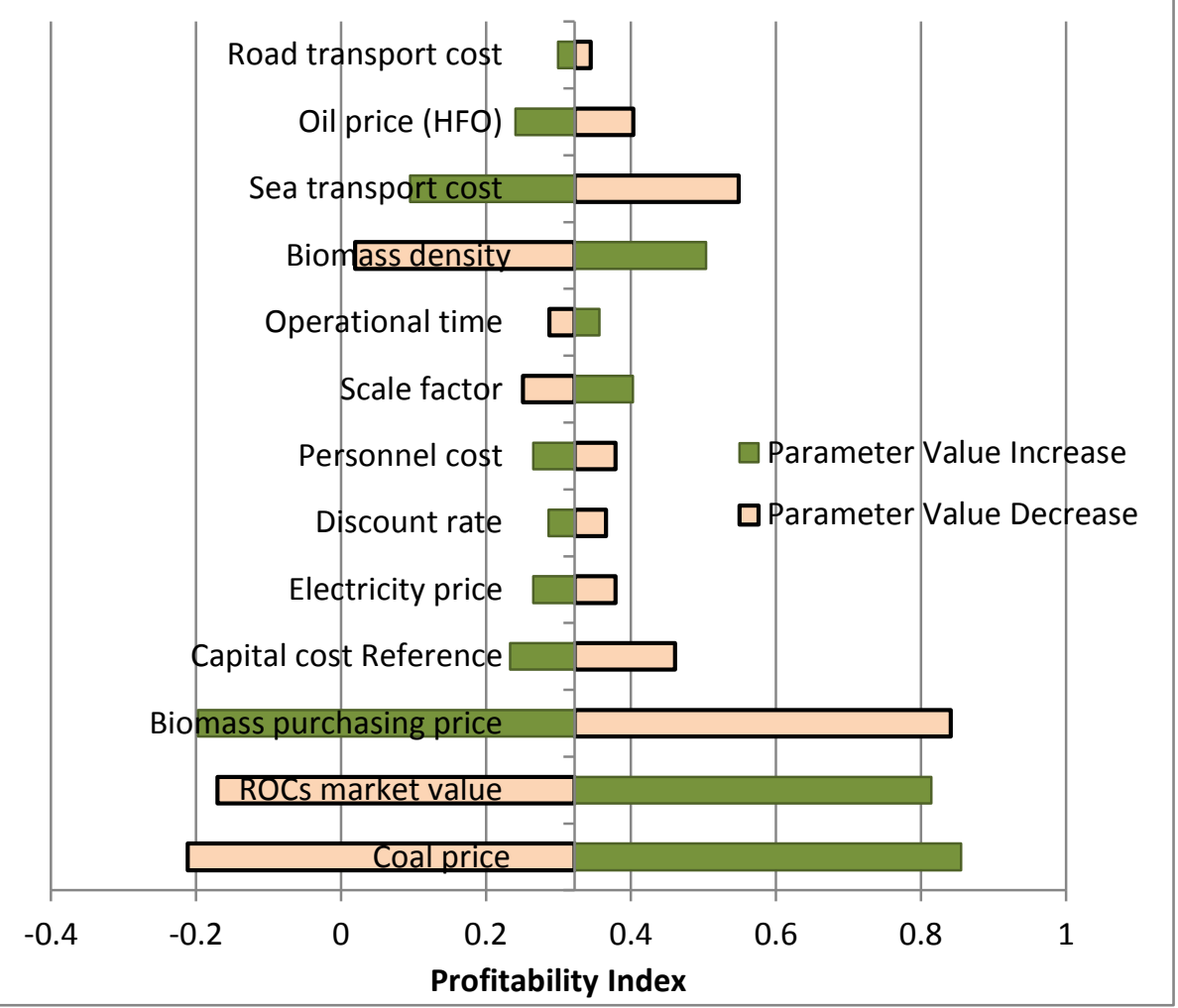

Figure 13 a. Sensitivity analysis for the $5 \%$ co-firing scenario

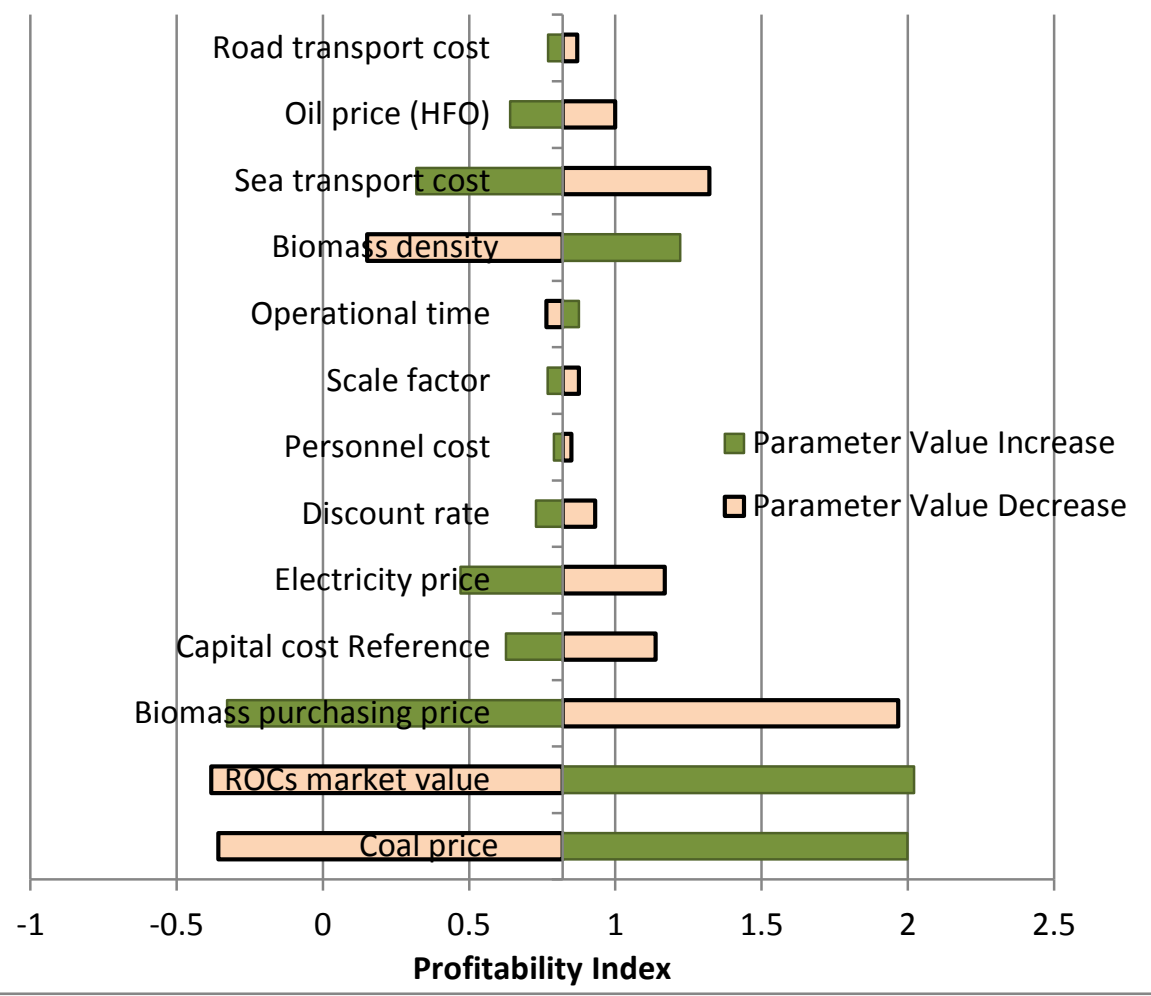

Figure $13 \mathrm{~b}$. Sensitivity analysis for the $50 \%$ co-firing scenario 


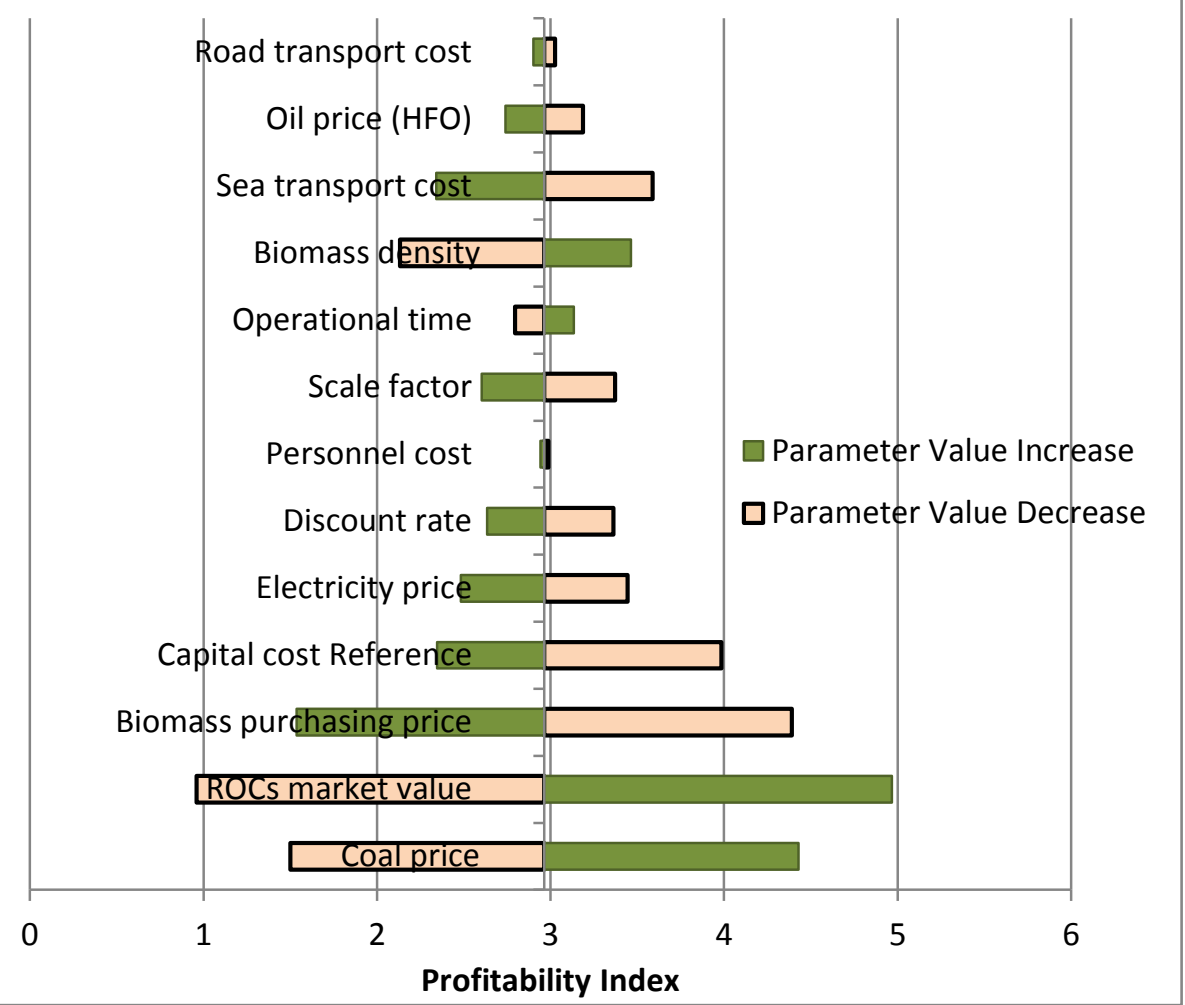

Figure $13 c$. Sensitivity analysis for the $100 \%$ biomass scenario

\subsection{Sensitivity analysis of revenue-related parameters}

Coal price appears to be the most influential parameter for the $5 \%$ co-firing scenario, and the second most influential for the higher co-firing ratio scenarios. Coal use reduction leads to savings that constitute an important revenue stream for all scenarios. Coal price has fluctuated significantly between $£ 32.61$ and $£ 80.14$ per ton since 2004 [38] and therefore significant uncertainty in future values can be expected. ROCs constitute the single most influential parameter in the $100 \%$ biomass scenario and the second most influential for the $5 \%$ scenario, whereas it has an almost equal effect to coal price for the $50 \%$ scenario. This is a direct effect of the higher number of ROCs granted for higher co-firing rates. Both coal and ROCs value increase by $25 \%$ render the $50 \%$ co-firing scenarios profitable and the $5 \%$ co-firing scenario close to being profitable. A decrease of $25 \%$ renders the $100 \%$ biomass scenario marginally profitable, especially in the case of ROCs, indicating very high sensitivity of the project to changes on the values of these parameters.

\subsection{Sensitivity analysis of torrefaction plant CAPEX/OPEX and operations-related parameters}

The most influential cost-related parameter is biomass purchasing price. A $25 \%$ decrease in biomass price makes the $50 \%$ co-firing scenario profitable and increases further the profitability of the $100 \%$ biomass scenario. The $5 \%$ co-firing scenario requires further biomass price decrease to become profitable. A $25 \%$ increase reduces significantly the profitability of the $100 \%$ biomass scenario, but does not make it unprofitable. This indicates the criticality of securing long-term contracts for lowcost biomass sources, particularly taking into account that competition for biomass resources will tend to increase in the future. Having said that, the technological system examined has the added advantage of being flexible in reverting back to coal-only operation if biomass prices increase to a 
level that it is not profitable to co-fire it any more, giving the operator a valuable risk mitigation option.

Capital cost is the second most influential cost-related parameter. For the scenarios of $5 \%$ co-firing and the $100 \%$ biomass its effect is more profound, whereas for the $50 \%$ co-firing a $25 \%$ decrease can make the project profitable. Since torrefaction is not an established technology yet, the investment cost data found in the literature is mostly based on estimations or pilot units; therefore, the actual cost could differ significantly.

Electricity price is the next most influential parameter for the $100 \%$ biomass scenario, due to the significant de-rating of the power plant. In cases of high electricity prices, the lost income due to derating affects significantly the profitability of the project and the effect is more intense for high cofiring rate scenarios.

The discount rate change has a similar effect to electricity price change on the $5 \%$ co-firing and $100 \%$ biomass scenarios, whereas it is less important in the $50 \%$ co-firing scenario. Therefore, identifying low interest rate funding solutions and reducing the investment risk to facilitate lower discount rates are important for this type of investments, especially when very low or very high co-firing ratios are considered.

The actual scale factor has a more significant effect in the cases of $5 \%$ co-firing and $100 \%$ biomass scenarios, where the size of the torrefaction plant differs significantly from the reference size. The personnel cost and the operational time of the plant are not considered critical for the profitability of the project for the ranges examined.

\subsection{Sensitivity analysis of supply system-related parameters}

This work has placed significant emphasis on the biomass supply system; therefore, the main related input parameters are discussed separately. Sea transportation cost is a major determinant of the project profitability, primarily due to the long distance involved. When the overall sea transportation cost is considered, a $25 \%$ increase can reduce the profitability of all scenarios significantly, whereas a $25 \%$ decrease turns the $50 \%$ co-firing scenario into profitability. This overall cost is primarily affected by the ship charter costs, which have been assumed equal to $\$ 8,000$ per day in this work but have fluctuated significantly from approximately $\$ 4,000$ to $\$ 16,000$ between the years 2011 and 2015 [44], as well as the fuel cost, with the value of HFO fluctuating from $\$ 216$ to $\$ 750$ per ton between 2008 and 2015 [39], with the assumed baseline value of $\$ 477$ per ton highly prone to significant changes. The HFO price itself has a measurable effect on the profitability of the project for all cofiring scenarios when examined in isolation, but the overall sea transportation cost is much more influential, indicating the charter cost as a more significant cost factor than fuel cost. It is interesting to note that it has been proposed that the biomass shipping strategy should align with the shipping rates to reduce the sea transportation cost, leading however to greater demand for storage space [45].

Biomass density is a factor that influences the sea transportation cost significantly, as the ship capacity is determined by the volume of the load for the case examined. Even in the case of $25 \%$ increase in the biomass density, volume is still restricting the ship capacity, but the project profitability is significantly enhanced. The $50 \%$ co-firing scenario becomes profitable if biomass 
density is increased by $25 \%$. Therefore, investors should pay close attention to the real biomass bulk density.

Road transportation cost changes do not impact significantly the project profitability, primarily because the largest part of the biomass will be transported using the existing resources currently used for coal leading to a small differential cost being accounted for the purposes of the investment analysis.

\section{Conclusion}

This work examines the feasibility of biomass torrefaction downstream in long-distance international bioenergy supply chains for co-firing in large-scale electricity generation coal-fired power plants. This is a novel concept that considers the trade-off between the disadvantage of less efficient longdistance sea transportation compared to the upstream torrefaction option and the advantages of lower capital investment requirement for the torrefaction facility and the power plant modifications, lower operational cost of the torrefaction process, higher overall system efficiency, elimination of supply chain and processing stages, and presenting the risk-mitigating option for the power plant operator to revert back to coal only operation if necessary. The effect of the biomass co-firing ratio on the feasibility of the system is also investigated, adopting a whole systems approach.

The results of application of the downstream torrefaction concept for a Palm Kernel Shell supply chain between Malaysia and the UK indicate several implications for potential investors: downstream torrefaction is profitable under the current UK biomass co-firing support regimes and market conditions only for the case of $100 \%$ biomass, which appears to be a particularly attractive investment opportunity. From the co-firing scenarios, the 50\% ratio has the best financial yield but still does not exhibit profitability.

The financial attractiveness of such an investment is very sensitive on the price of coal and ROCs, where a $25 \%$ reduction of their value can decrease the yield of all co-firing ratio scenarios significantly and even render the $100 \%$ biomass scenario marginally profitable. Regarding the cost factors, biomass purchasing cost is the most influential, followed by the torrefaction facility investment cost and the sea transportation cost. As all above parameters are characterised by high uncertainty due to varying reasons, careful consideration of the risk involved should be given and mitigation measures considered. Although the most attractive scenario of $100 \%$ biomass does not become unprofitable with any of the parameters changing by $25 \%$ in isolation, changing more than one parameter by this level could threaten its profitability.

From a policy maker perspective, the results indicate the possibility for regulators to promote $50 \%$ co-firing ratios rather than the current practice of $100 \%$ biomass conversion of coal-fired units with virtually the same cost, as the marginal cost per actual $\mathrm{CO}_{2}$ unit reduction is almost the same between the two cases. The advantage the $50 \%$ co-firing ratio has over the $100 \%$ biomass is added environmental benefits due to lower supply system emissions per unit of renewable energy delivered and higher electricity output per unit of biomass used. The $5 \%$ co-firing ratio is also identified as an interesting prospect, as the marginal cost difference from the $100 \%$ biomass scenario is only $3.7 \%$, while the environmental benefits are further enhanced compared to the $50 \%$ co-firing ratio scenario. 
From an environmental perspective, the whole supply system accounts for $\mathrm{CO}_{2}$ emissions due to fossil fuel use equal to $6.93 \%-7.94 \%$ of the total emissions reduction, with higher co-firing ratios leading to higher emissions per unit of renewable energy generated. Low co-firing ratios are a more environmentally friendly solution, due to avoidance of power plant de-rating and subsequent efficiency reduction, when seen from a whole system's perspective.

The investment analysis results of this work apply to the specific case supply chain examined, which is one of the longest-distance supply chains that can be practically implemented, and thus can be considered as the worst case scenario in terms of transportation distance. Despite the fact that these findings cannot be directly generalised to other biomass types or supply chains, insights can be drawn from the sensitivity analysis performed for most of the influential system parameters. On the other hand, the trends identified when analysing the effects of varying co-firing ratios to the supply chain are expected to be valid in other torrefaction-based supply chains too.

\section{References}

[1] European Commission. Renewable Energy Progress Report. 2015.

[2] Department of Energy \& Climate Change. UK Renewable Energy Roadmap. 2011.

[3] Department of Energy \& Climate Change. UK Bioenergy Strategy. 2012.

[4] DECC. Renewable energy planning database monthly extract - April 20162016.

[5] Uslu A, Faaij AP., Bergman PC. Pre-treatment technologies, and their effect on international bioenergy supply chain logistics. Techno-economic evaluation of torrefaction, fast pyrolysis and pelletisation. Energy 2008;33:1206-23. doi:10.1016/j.energy.2008.03.007.

[6] Hamelinck CN, Suurs RAA, Faaij APC. International bioenergy transport costs and energy balance. Biomass and Bioenergy 2005;29:114-34. doi:10.1016/j.biombioe.2005.04.002.

[7] Ehrig R, Behrendt F. Co-firing of imported wood pellets - An option to efficiently save CO2 emissions in Europe? Energy Policy 2013;59:283-300. doi:10.1016/j.enpol.2013.03.060.

[8] Batidzirai B, van der Hilst F, Meerman H, Junginger M, Faaij A. Optimization potential of biomass supply chains with torrefaction technology. Biofuels, Bioprod Biorefining 2014;8:253-82. doi:10.1002/bbb.1458.

[9] Damen K, Faaij A. A greenhouse gas balance of two existing international biomass import chains: The case of residue co-firing in a pulverised coal-fired power plant in the Netherlands. Mitig Adapt Strateg Glob Chang 2006;11:1023-50. doi:10.1007/s11027-006-9032-y.

[10] Irena - lea - Etsap. Biomass Co- firing: Technology Brief. 2013.

[11] Nunes LJR, Matias JCO, Catalao JPS. A review on torrefied biomass pellets as a sustainable alternative to coal in power generation. Renew Sustain Energy Rev 2014;40:153-60. doi:10.1016/j.rser.2014.07.181. 
[12] Kongkeaw N, Patumsawad S. Thermal Upgrading of Biomass as a Fuel by Torrefaction. 2nd Int. Conf. Environ. Eng. Appl., vol. 17, 2011, p. 38-42.

[13] Arias B, Pevida C, Fermoso J, Plaza MG, Rubiera F, Pis JJ. Influence of torrefaction on the grindability and reactivity of woody biomass. Fuel Process Technol 2008;89:169-75. doi:10.1016/j.fuproc.2007.09.002.

[14] Bergman PC., Boersma A., Zwart RW., Kiel JH. Torrefaction for biomass co-firing in existing coal-fired power stations. 2005.

[15] Li J, Brzdekiewicz A, Yang W, Blasiak W. Co-firing based on biomass torrefaction in a pulverized coal boiler with aim of 100\% fuel switching. Appl Energy 2012;99:344-54. doi:10.1016/j.apenergy.2012.05.046.

[16] Thrän D, Witt J, Schaubach K, Kiel J, Carbo M, Maier J, et al. Moving torrefaction towards market introduction - Technical improvements and economic-environmental assessment along the overall torrefaction supply chain through the SECTOR project. Biomass and Bioenergy 2016;89. doi:10.1016/j.biombioe.2016.03.004.

[17] Batidzirai B, Mignot AP., Schakel WB, Junginger HM, Faaij AP. Biomass torrefaction technology: Techno-economic status and future prospects. Energy 2013;62:196-214. doi:10.1016/j.energy.2013.09.035.

[18] Mobini M, Meyer JC, Trippe F, Sowlati T, Fröhling M, Schultmann F. Assessing the integration of torrefaction into wood pellet production. J Clean Prod 2014;78:216-25. doi:10.1016/j.jclepro.2014.04.071.

[19] Svanberg M, Olofsson I, Flodén J, Nordin A. Analysing biomass torrefaction supply chain costs. Bioresour Technol 2013;142:287-96. doi:10.1016/j.biortech.2013.05.048.

[20] Hall WJ. Assessment of carbon dioxide emissions reductions achievable by using torrefaction. J Energy Inst 2012;85:103-13. doi:10.1179/1743967112Z.00000000020.

[21] Shah A, Darr M, Medic D, Anex R, Khanal S, Maski D. Techno-economic analysis of a production-scale torrefaction system for cellulosic biomass upgrading. Biofuels, Bioprod Biorefining 2012;6:45-57. doi:10.1002/bbb.336.

[22] INL-PNNL. Technical Report: Logistics, Costs, and GHG Impacts of Utility-Scale Cofiring with 20\% Biomass. 2013.

[23] Sea Distances n.d. http://www.sea-distances.org/ (accessed December 15, 2015).

[24] Gardbro G. Techno-economic modeling of the supply chain for torrefied biomass. Umeå University, 2014.

[25] Qian Y, Mcdow W. The Wood Pellet Value Chain. 2013.

[26] Rentizelas A, Tolis A, Tatsiopoulos I. Logistics issues of biomass: The storage problem and the multi-biomass supply chain. Renew Sustain Energy Rev 2009;13:887-94.

doi:10.1016/j.rser.2008.01.003. 
[27] UNFCCC. EB41 - Annex 11: Methodological Tool: Tool to calculate project or leakage CO2 emissions from fossil fuel combustion v. 02. 2008.

[28] Rightship. Calculating and Comparing CO2 Emissions from the Global Maritime Fleet. 2013.

[29] UNFCCC. Tool 12: Methodological tool: Project and leakage emissions from transportation of freight, v.01.1.0. 2012.

[30] Hekkert M, Hendriks F, Faaij A, Neelis M. Natural gas as an alternative to crude oil in automotive fuel chains well-to-wheel analysis and transition strategy development. Energy Policy 2005;33:579-94. doi:10.1016/j.enpol.2003.08.018.

[31] Hess R, Kenney K, Ovard L, Searcy E, Wright C. Commodity-Scale Production of an Infrastructure-Compatible Bulk Solid from Herbaceous Lignocellulosic Biomass. 2009.

[32] Li J, Zhang X, Pawlak-Kruczek H, Yang W, Kruczek P, Blasiak W. Process simulation of co-firing torrefied biomass in a 220MWe coal-fired power plant. Energy Convers Manag 2014;84:50311. doi:10.1016/j.enconman.2014.04.075.

[33] UNFCCC. Approved consolidated baseline and monitoring methodology ACM0020 "Co-firing of biomass residues for heat generation and/or electricity generation in grid connected power plants." 2011.

[34] Rentizelas AA, Tolis Al, Tatsiopoulos IP. Optimisation and investment analysis of two biomassto-heat supply chain structures. Biosyst Eng 2014;120:81-91.

doi:10.1016/j.biosystemseng.2013.07.012.

[35] Ofgem. Renewables Obligation : Guidance for Generators. 2015.

[36] Eurostat. Producer prices in industry, domestic market, EU-28 2015.

[37] Pirraglia A, Gonzalez R, Saloni D, Denig J. Technical and economic assessment for the production of torrefied ligno-cellulosic biomass pellets in the US. Energy Convers Manag 2013;66:153-64. doi:10.1016/j.enconman.2012.09.024.

[38] UK Government. Prices of fuels purchased by major power producers 2014. https://www.gov.uk/government/statistical-data-sets/prices-of-fuels-purchased-by-majorpower-producers.

[39] Bunkerworld. BW380 Bunkerworld Index 2015. http://www.bunkerworld.com/.

[40] European Commission. Quarterly Report on European Electricity Markets. vol. 7 (3). 2014.

[41] Eurostat. UK average manufacturing hourly cost \& hours paid. 2012.

[42] Sokhansanj S, Kumar A, Turhollow A. Development and implementation of integrated biomass supply analysis and logistics model (IBSAL). Biomass and Bioenergy 2006;30:838-47. doi:10.1016/j.biombioe.2006.04.004.

[43] Forsberg G. Biomass energy transport: analysis of bioenergy transport chains using life cycle inventory method. Biomass and Bioenergy 2000;19:17-30. 
[44] BIMCO. Time charter average rates for dry bulk vessels n.d. https://www.bimco.org (accessed January 15, 2016).

[45] Svanberg M, Halldórsson Á. Supply chain configuration for biomass-to-energy: the case of torrefaction. Int J Energy Sect Manag 2013;7:65-83. doi:http://dx.doi.org/10.1108/17506221311316489. 


\section{Figure captions}

Figure 1. PKS supply chain schematic

Figure 2. The flow chart of the co-firing plant with integrated biomass torrefaction

Figure 3. Net Present Value of co-firing scenarios examined

Figure 4. Profitability Index of co-firing scenarios examined

Figure 5. Breakdown of annual revenue

Figure 6. Breakdown of expenditure

Figure 7. Marginal cost of reducing $\mathrm{CO}_{2}$ emissions

Figure 8. Renewable energy (electricity) generated per unit of biomass

Figure 9. Total annual net $\mathrm{CO}_{2}$ emissions reduction

Figure 10. $\mathrm{CO}_{2}$ emissions from biomass logistics stages

Figure 11. Logistics $\mathrm{CO}_{2}$ emissions compared to overall system $\mathrm{CO}_{2}$ savings

Figure 12. Primary energy use for production and logistics operations of PKS

Figure $13 a$. Sensitivity analysis for the $5 \%$ co-firing scenario

Figure $13 \mathrm{~b}$. Sensitivity analysis for the $50 \%$ co-firing scenario

Figure $13 c$. Sensitivity analysis for the $100 \%$ biomass scenario 